\title{
Robotics and Remote Systems Applications
}

by

D. E. Rabold

Westinghouse Savannah River Company

Savannah River Site

Aiken, South Carolina 29808

RECENED

DEC 151995

USTI

A document prepared for HOME PAGE

DOE Contract No. DE-AC09-89SR18035

This paper was prepared in connection with work done under the above contract number with the U.S.

Department of Energy. By acceptance of this paper, the publisher and/or recipient acknowledges the U.S. Government's right to retain a nonexclusive, royalty-free license in and to any copyright covering this paper, along with the right to reproduce and to authorize others to reproduce all or part of the copyrighted paper. 


\section{Savannah River Technology Center}

\section{Robotics and \\ Remote Systems Applications}

Savannah River Technology Center

Operated for the U.S. Department of Energy by Westinghouse Savannah River Company 


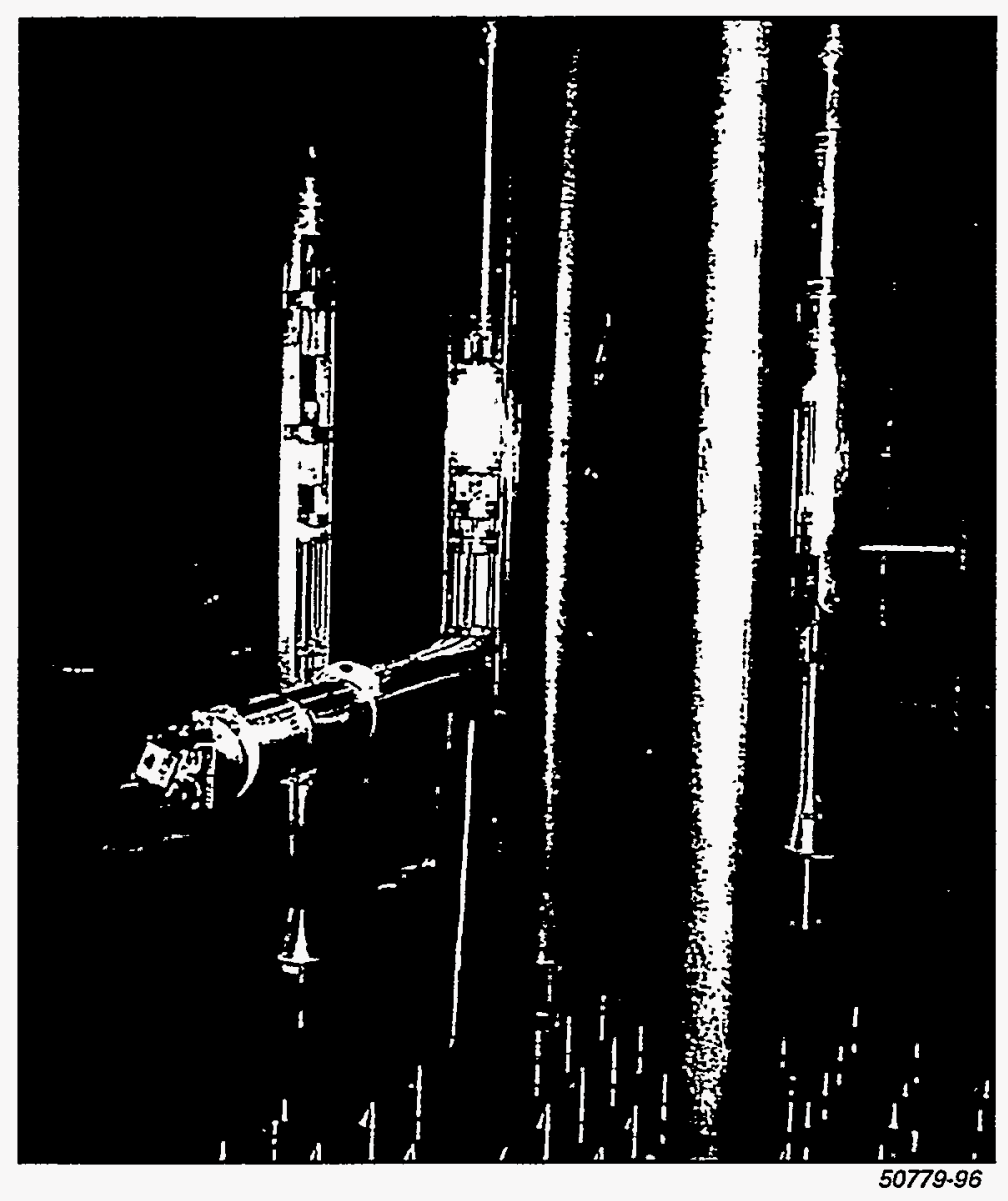

\section{Reactor Tank Inspection Robot}

Inspection of welds was required to determine structural integrity of reactor vessels in $\mathrm{P}, \mathrm{K}$, and L Area before startup. SRTC developed a system to perform these inspections and successfully operated this system in all three reactor vessels. The system included 4 fiveaxis robotic inspection tools, 6 three-axis camera and lighting masts, video equipment, data acquisition systems, mobile control center, and ultrasonic and eddy current sensors. In-tank radiation was $1,000 \mathrm{R} / \mathrm{hr}$ to $100,000 \mathrm{R} / \mathrm{hr}$. Access into the reactor vessel is through 4.38 inch diameter openings. Areas to be scanned were 6 to 21 feet below the access point. The accuracy of the robot at the tank is \pm 0.030 inch. The remote inspection robot and camera positioner were installed in multiple openings to complete the inspection of each vessel and were controlled from the mobile control center parked outside the reactor building 200 feet from the vessel. The development and operation of the system was completed ahead of schedule and below budget. 


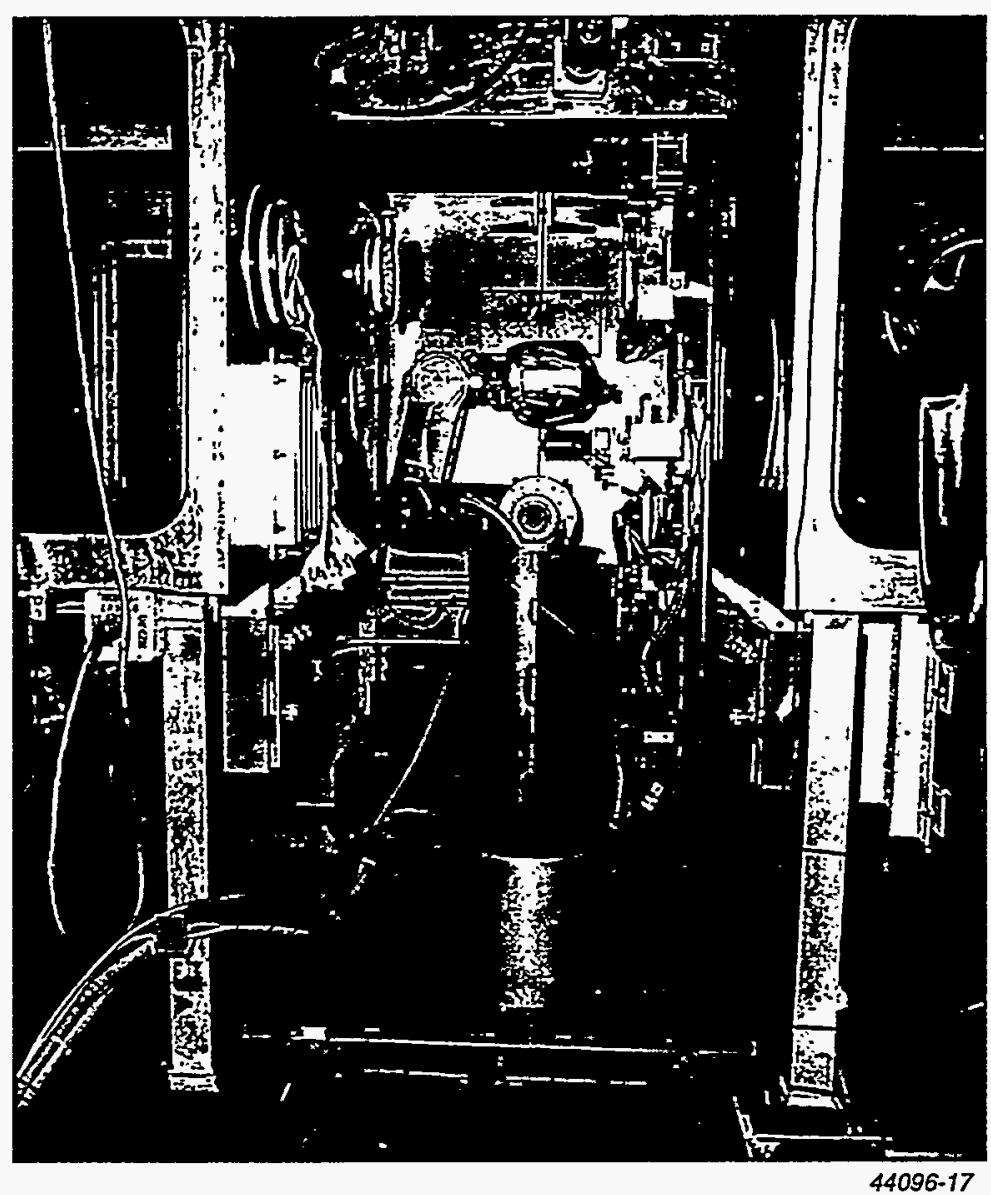

\section{Californium Waste Removal Robot}

SRTC developed a robot system to bag-out and remove the radioactive waste containers from the Californium Processing Facility. The system is composed of an industrial five-axis robot, an SRTC designed end effector, and an automatic bag-gathering and clipping machine. The robot reaches through a port into a glovebox through a sealed plastic bag, grabs the one-gallon can of Californium waste and pulls it through the port. The robot then rotates the can to twist the plastic bag. The bag-gathering machine then places a clip on the bag, the robot pulls the bag out a little further, a second clip is placed on the bag and then the bag is cut between the clips. This seals the can in the bag and seals the port. The robot then places up to four cans in a drum. The drum is lifted by overhead crane and placed into a shielded cask. The entire operation is controlled and monitored by technicians viewing the operation on monitors in a separate room. This robot system is estimated to have saved 35 rem of exposure to personnel. 


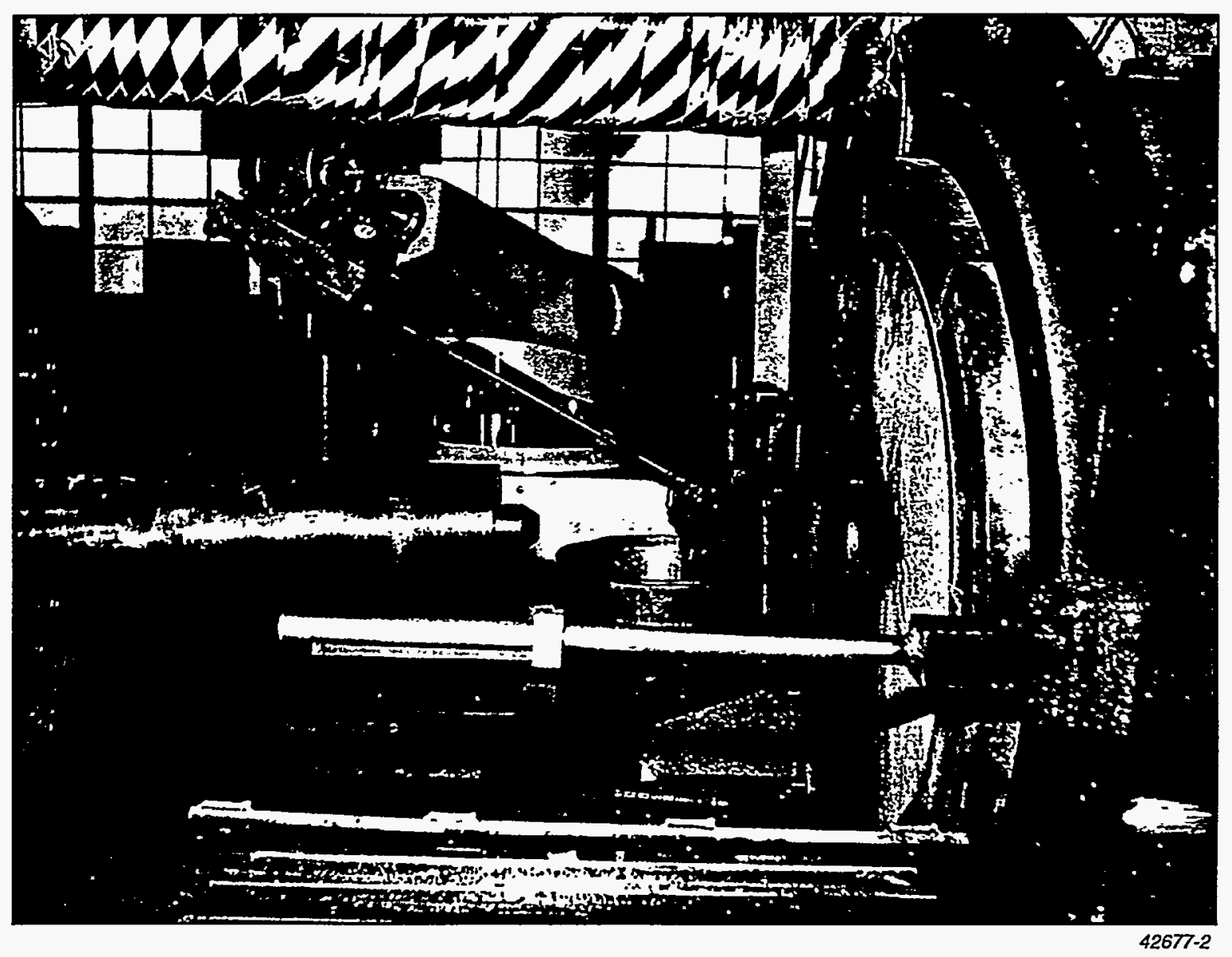

\section{Fuel Rod Lubrication Robot}

SRTC developed, installed, and started up a Unimate 2571-B robot to lubricate the extrusion press in the SRS Materials Area. Manual lubrication of the press was a physically demanding job with safety concerns due to the high temperatures and forces involved and the long, heavy swab used for applying the lubricant consisting of lead powder suspended in oil. The robot was placed on rails to permit withdrawal for container and die changeouts and reversion to manual operation, if required. The robot was interlocked with the press and each phase of operation was initiated by the operator via a control panel. The end effector included a motor for rotating the swab and it was spring-loaded for compliance during lubricant application. After initial tests, a lubrication delivery system that meters a fixed volume of lubricant per cycle was installed that provided uniformity of the lubricant automated system. 


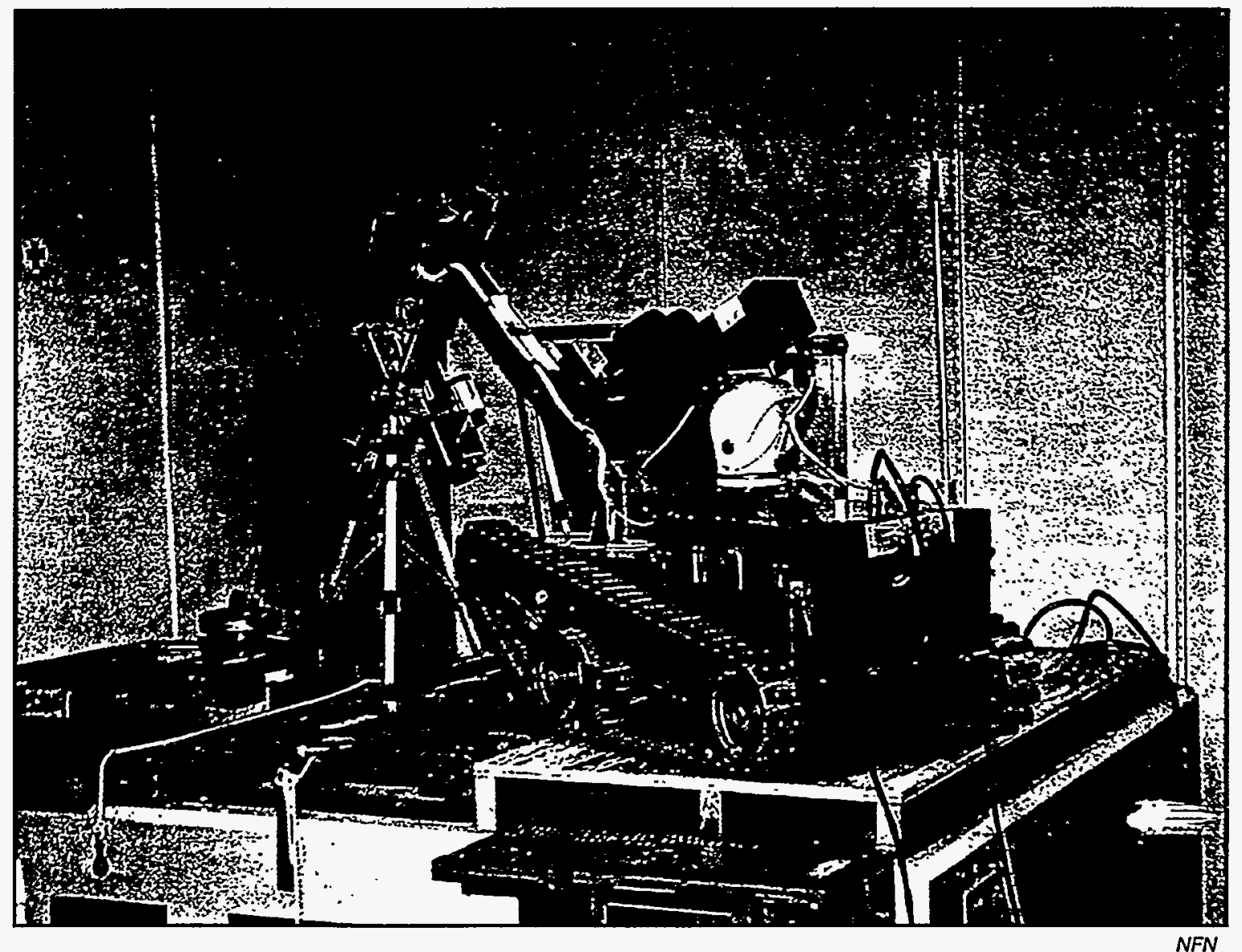

\section{Cesium Source Manipulation}

SRTC provided an OAO-150 mobile teleoperator to manipulate a 55-curie cesium source located in a well. The source is used to calibrate radiation detection equipment. The transport system for moving the source up and down in the well failed. Since the source was over $800 \mathrm{R} / \mathrm{hr}$ at the surface, it had to be removed and replaced remotely to allow manual repair of the transport system. The OAO-150 was chosen because of its relatively small size and it has a multi-jointed arm capable of operating in the narrow confines of the cesium well. This mobile teleoperator was used for this operation on three different occasions between 1991 and 1994 without any appreciable radiation exposure to personnel.

The OAO-150 is a tracked, skid-steered mobile teleoperator that can be operated by either radio-control or tether cable. The vehicle has a five degree-of-freedom joint-controlled manipulator arm with a parallel jaw gripper. SRTC developed the concept for manipulation of the source, helped develop the procedure and trained operators in its use. SRTC modified the gripper to perform both tweezer-like gripping for the source and heavy lifting of a shielding plug. All operations were controlled from a remote, shielded room using video provided by SRTC utilizing two cameras on the vehicle and tripod-mounted cameras that were strategically placed in the room containing the cesium well. Because of the strength of the cesium source, the manipulator placed it behind 6 inches of lead shielding while the transport system was repaired. 


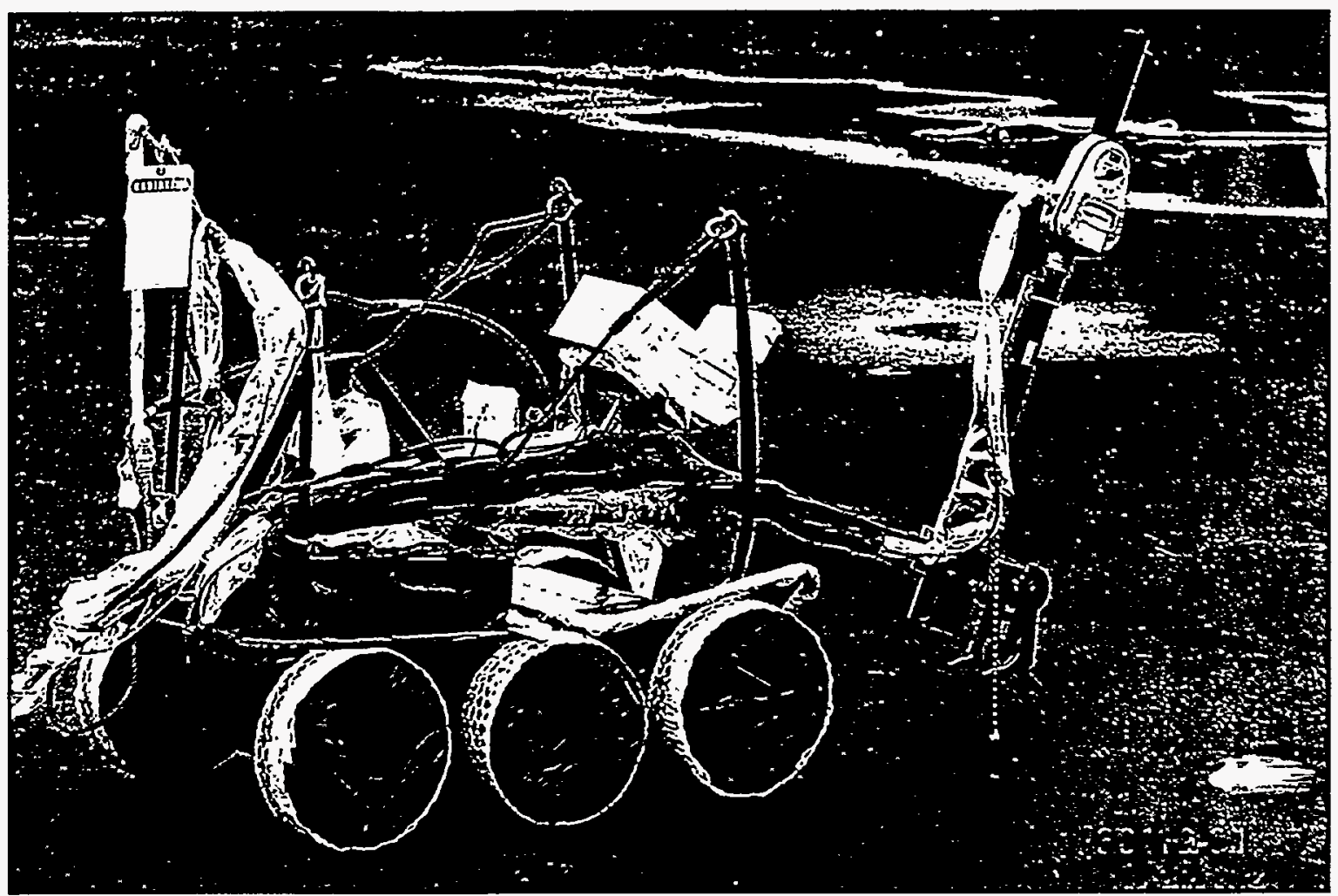

38119-31

\section{Tank 13 Survey}

After a radioactive spill occurred on the top of one of the waste storage tanks at SRS, Tank 13, SRTC was requested to provide equipment for a remote survey of the tank top and surrounding area to determine the level and extent of the spill. SRTC modified an existing mobile teleoperator, originally designed for remote bomb disposal, to perform this task. A lifting cable was added to the vehicle to allow retrieval by crane, if the unit were unable to return for any reason. A radiation detector with a remote readout was mounted to the arm to allow manipulation of the detector. The entire unit was sealed in plastic film to prevent contamination. This system was developed, demonstrated and deployed in less than two weeks. The system was used for a few days to provide a very comprehensive survey of the tank top without any significant exposure of personnel. General rates ranged from $10 \mathrm{mR} / \mathrm{hr}$ to $600 \mathrm{mR} / \mathrm{hr}$, with hot spots ranging from $500 \mathrm{mR} / \mathrm{hr}$ to $10 \mathrm{R} / \mathrm{hr}$. This data was used for knowledgeable planning of the cleanup for which robotics were also employed. 


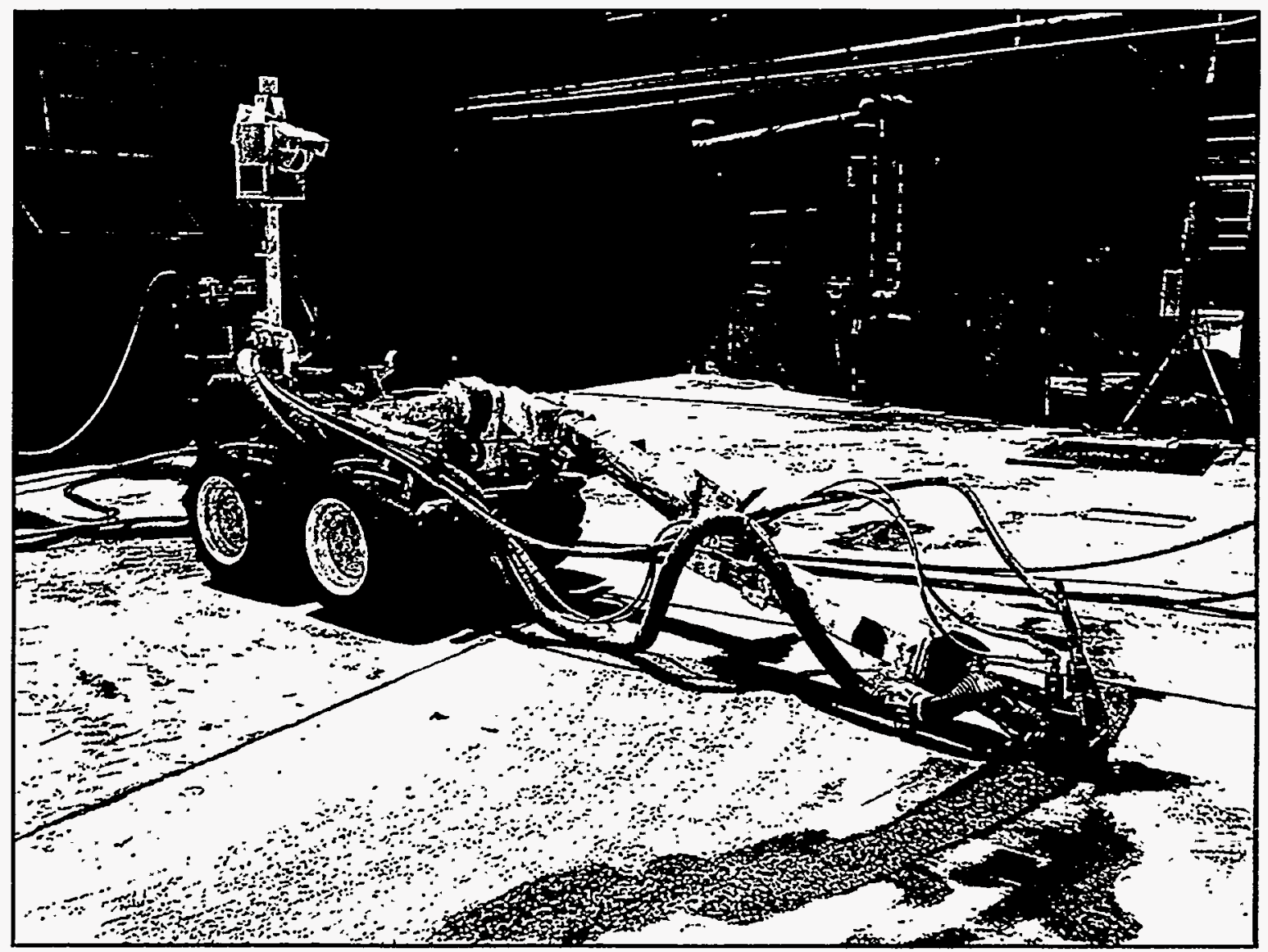

46213-11

\section{Tank 13 Decontamination}

After an SRTC mobile teleoperator was used to survey a spill of radioactive liquid waste on the top of SRS Tank 13, it was determined that decontamination of the concrete was required. General rates ranged from $10 \mathrm{mR} / \mathrm{hr}$ to $600 \mathrm{mR} / \mathrm{hr}$, with hot spots ranging from $500 \mathrm{mR} / \mathrm{hr}$ to $10 \mathrm{R} / \mathrm{hr}$. SRTC outfitted a radio-controlled, diesel-engine-powered TSR-700 mobile teleoperator, manufactured by 21 st Century/Sivan, with a concrete scabbling head, manufactured by Admac. The Admac system removes the surface layer of concrete by using water at 35,000 to $55,000 \mathrm{psi}$. This system was used successfully by the West Valley Demonstration Project for concrete decontamination. The high pressure spray head was modified with a shroud and vacuum attachment, which extracted all expended water and removed concrete into a collection tank. The modified head, which cleans a 3 inch swath, was attached directly to the manipulator. The head was moved in a semicircular path with the manipulator shoulder joint and the vehicle was moved after each pass to clean an overlapping area. The general area dose rates were reduced by factors of 3 to 5 . The total personnel exposure to complete the decontamination work was 1.7 rem. 


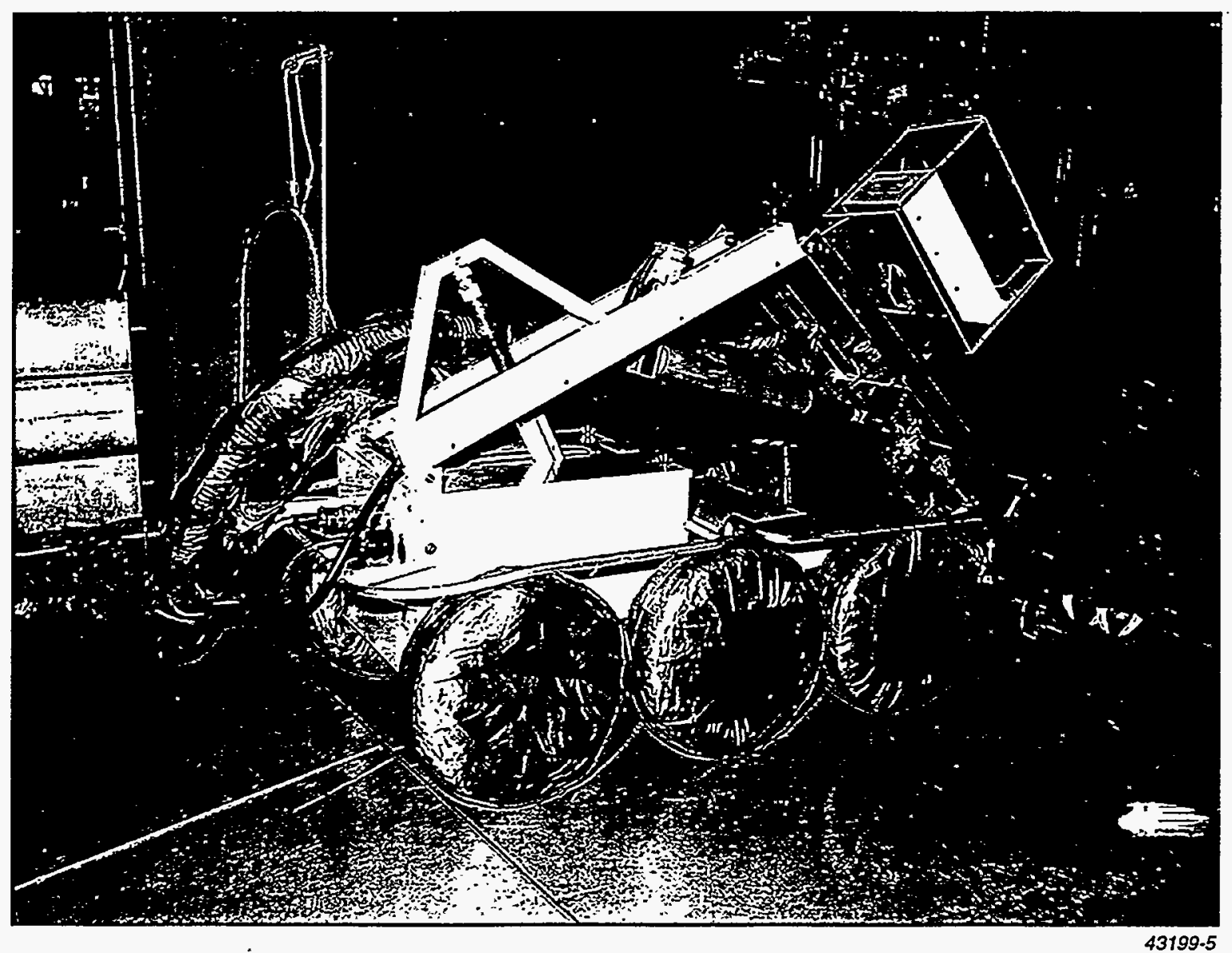

\section{Hot Gang Valve Corridor Decontamination}

A leak of radioactive liquid from the F-Area Hot Canyon into the Hot Gang Valve Corridor contaminated a large section of the corridor, including the ceiling, walls, equipment, and floor. Gamma dose rates at the ceiling were up to $100 \mathrm{R} / \mathrm{hr}$ and contamination on equipment ranged from $500 \mathrm{mR} / \mathrm{hr}$ to $4 \mathrm{R} / \mathrm{hr}$. Floor rates were $1 \mathrm{R} / \mathrm{hr}$ to $5 \mathrm{R} / \mathrm{hr}$ after being covered with lead sheets. As a result of the leak and the high radiation levels, routine operations and maintenance in the corridor stopped.

SRTC provided an RMI-3, manufactured by Pedsco of Canada, to perform the cleanup. The RMI-3 was modified so that it could remove the lead sheeting in the corridor. A Kelly System superheated water decontamination system from Container Products Corporation was used to decontaminate the ceiling, walls, equipment, and floor. The spray head was attached to the manipulator to clean the area. Cameras on board the teleoperator were augmented by additional cameras mounted in the corridor. By spraying with water and a mild caustic cleaning agent the radiation levels were reduced by a factor of 10 to 20 in most places. Some areas where paint had been worn away allowed the contamination to penetrate into the concrete. Levels of up to $5 \mathrm{R} / \mathrm{hr}$ remained in these areas and had to be removed manually by more aggressive means. These operations reduced the background radiation to a point where an internally contaminated junction box was identified that was subsequently removed by another SRTC provided mobile teleoperator. 

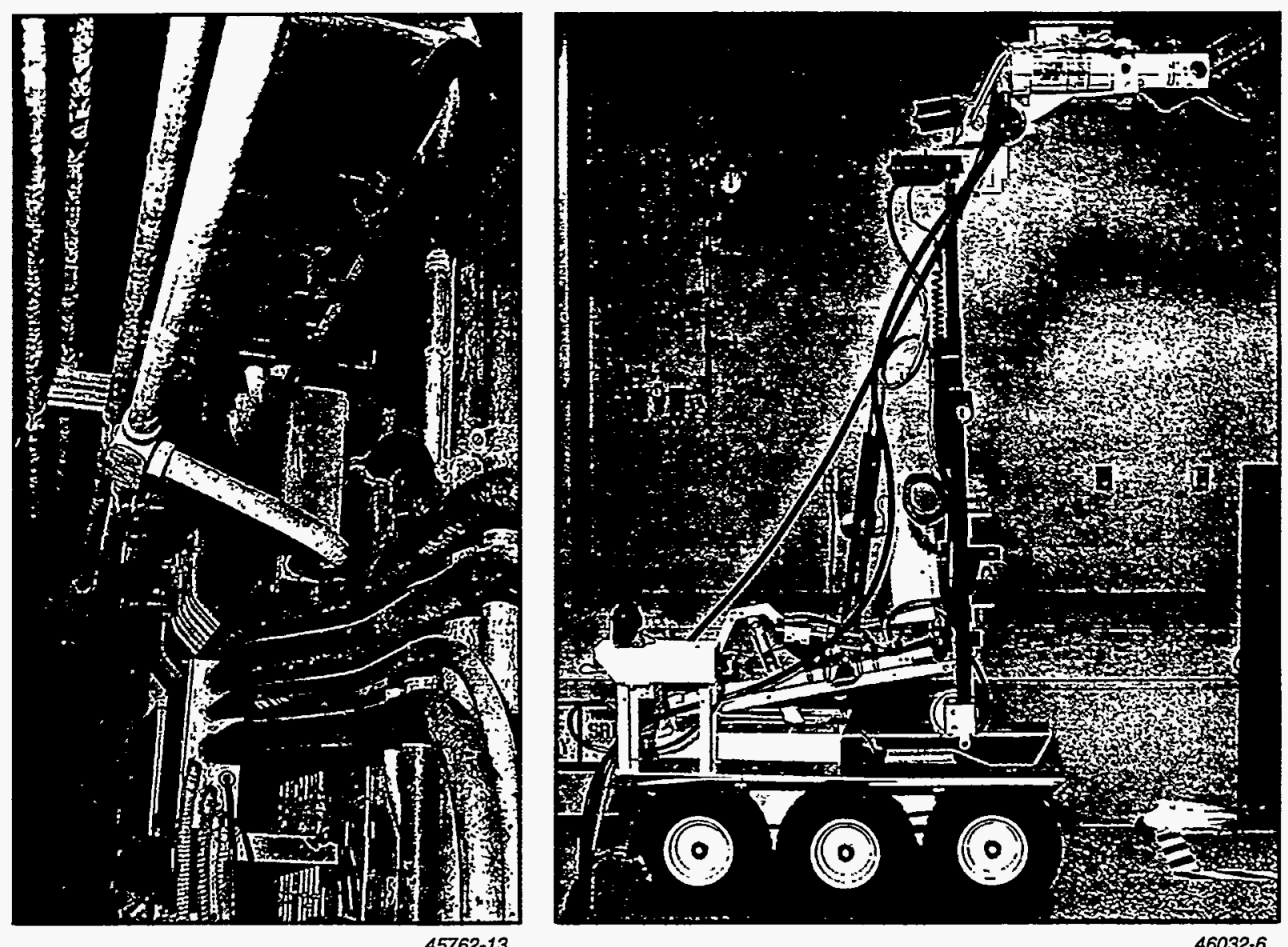

Hot Gang Valve Corridor Junction Box Removal

A modified RMI-3 mobile teleoperator, manufactured by Pedsco, was used to remove a wall mounted process junction box that a leak of radioactive liquid had contaminated to a level of $200 \mathrm{R} / \mathrm{hr}$. The junction box was in the Hot Gang Valve Corridor in the SRS F-Area Canyon building. The contaminated junction box was identified after the radiation level in the surrounding area was reduced by decontamination with another SRTC provided mobile teleoperator. The remote method produced much less exposure than the estimated $8 \mathrm{R}$ of exposure to perform the job manually.

SRTC extensively modified the mobile teleoperator to manipulate a hydraulic cutter capable of cutting through $5 \mathrm{~cm}$ ( 2 in) conduit. A new upper arm was built with its elbow down, a tool-mounted camera was installed and two additional degrees-of-freedom were added; a wrist rotate and wrist pitch. Operators developed techniques for removing the junction box in a simulated section of the corridor. Fifteen cuts were required to remove the junction box from the wall. Two of the fifteen remote cuts were incomplete, so they were finished manually because of small dimensional differences in the contaminated junction box and the mock-up box. Even with the manual cuts, total radiation exposure for this task was less than $1 R$. 


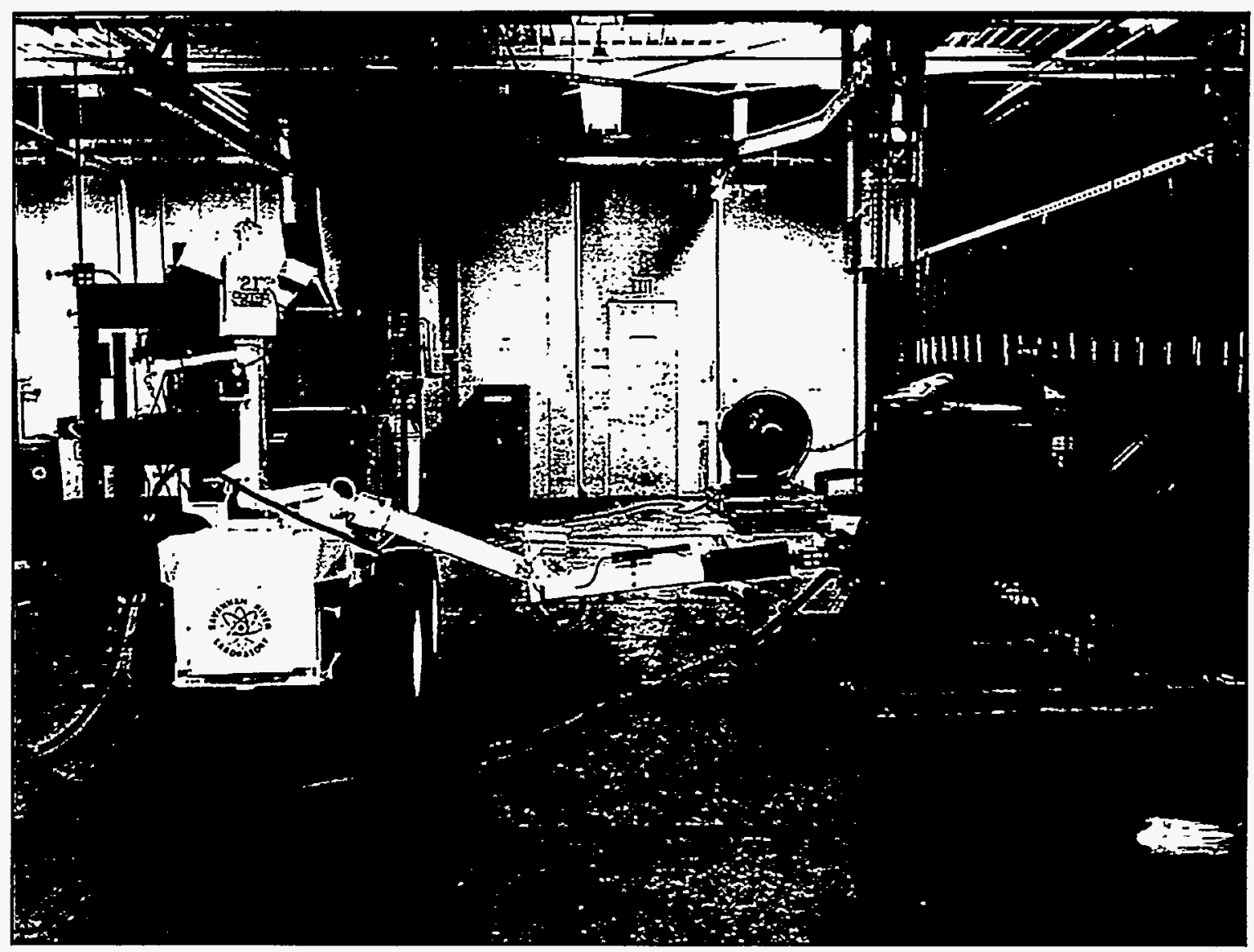

$44320-7$

\section{Removal of Lead from Deionizer Vessels}

A TSR-700 mobile teleoperator, manufactured by 21 st Century/Sivan, was used to remove lead shot used as counterweights on 10 reactor ion exchange process vessels, commonly referred to as deionizer vessels. The lead had to be removed from the vessels before the State of South Carolina would allow the vessels to be sent to the burial ground. The lead shot was contained in sealed stainless steel containers on the side of the vessels. Radiation levels measured as much as $5 \mathrm{R} / \mathrm{hr}$ on the surface of the vessels. However, remote operation resulted in no exposure to personnel.

The TSR-700 is a 4-wheel-drive, hydraulically-actuated vehicle with a 6 degree-of-freedom manipulator. The SRTC Robotics Group developed a special end effector for this application in a few weeks and trained Reactor area personnel to perform the task. Six remote video cameras were used to aid in navigation and positioning during operation. The end effector included a pneumatic-powered grinder positioned by a pneumatic cylinder. The end effector was spring loaded for compliance with the box. After cutting the side and bottom of each box, the manipulator gripper was used to pry open the box so that the lead shot fell into a catch pan. The manipulator then picked up a camera to videotape the inside of the empty box for documentation. This technique allowed two vessels to be processed each day. 


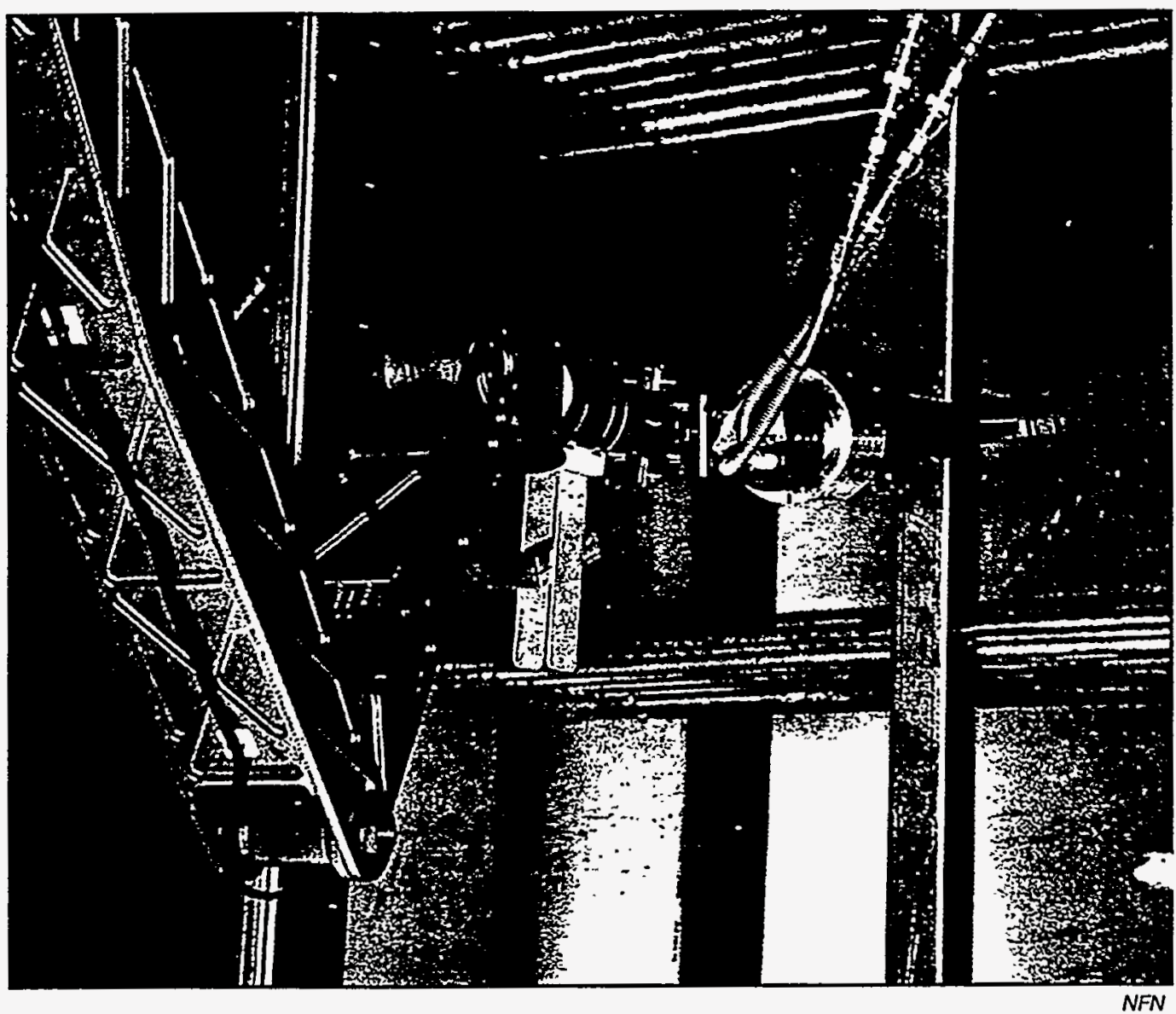

\section{Old HB Line Cleanup}

SRTC is developing a manipulator system to cleanup a glovebox in old HB line with radiation levels up $5 \mathrm{R} / \mathrm{hr}$. The system is composed of a Schilling manipulator mounted on a translation table. Several tools are being developed including; hydraulic sheer, abrasive wheel grinder, impact wrench, vacuum panel lifting tool, vacuum cleaning tool and various scoops. All the tools have been designed for remote grasping, use, and return by the manipulator. The grinder is being designed for remote replacement of grinding wheels. The panel lifting tool will allow removal of glass and steel panels on the front of the box for access to the interior. The translation table moves the manipulator towards the glovebox to provide the reach necessary to access all areas of the glovebox interior. This system will augment manual cleanup which has been accomplished on gloveboxes with much lower radiation levels. This work will include removal of radioactive contamination in the bottom of the box, and removal and size reduction of components including piping, valves, tanks, and supports. 


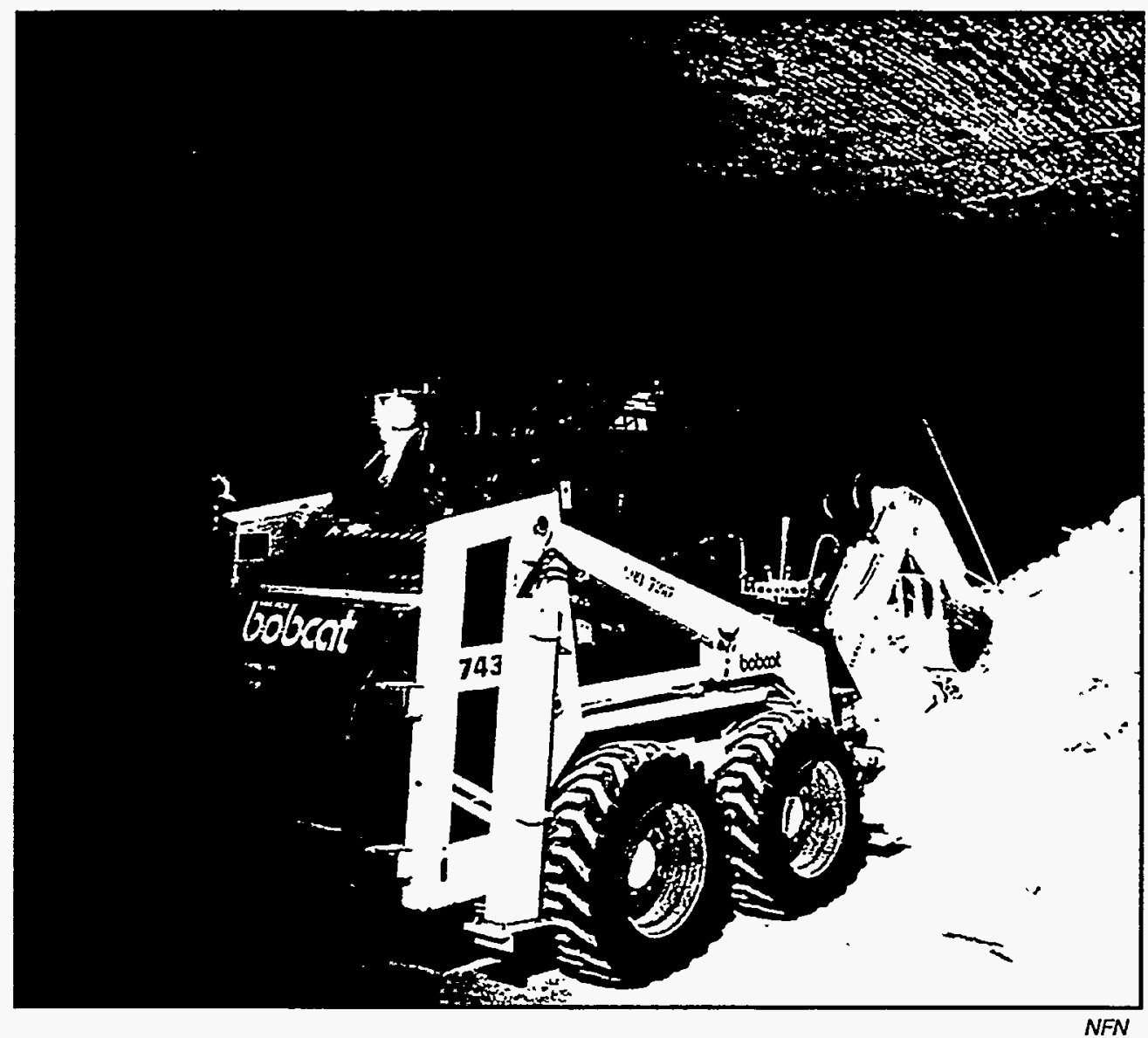

\section{WIPP Front End Loader Demonstration}

A radio-controlled BOBCAT front end loader and remote video system from SRTC were demonstrated removing debris in an accident scenario at the Waste Isolation Pilot Plant (WIPP) facility in New Mexico. The demonstration was in response to a court injunction against start up of the WIPP facility. The remote-controlled backhoe attachment on the BOBCAT proved very useful in the WIPP demonstration.

WIPP operators, trained by SRTC, easily controlled the vehicle by using joysticks to drive all proportionally controlled features of the vehicle, including the backhoe attachment. Four cameras were mounted on the vehicle by SRTC; three located above the cab with two directed forward and one directed back and one camera mounted on the backhoe. These cameras assisted the operators in maneuvering the vehicle and excavating at the site. Additional tripod mounted cameras and video equipment supplied by SRTC assisted in the demonstration. The video equipment supplied by SRTC was used to help navigate and direct the operation of other remotely controlled equipment in the demonstration. The video signals were transmitted over a microwave link to the operator. 


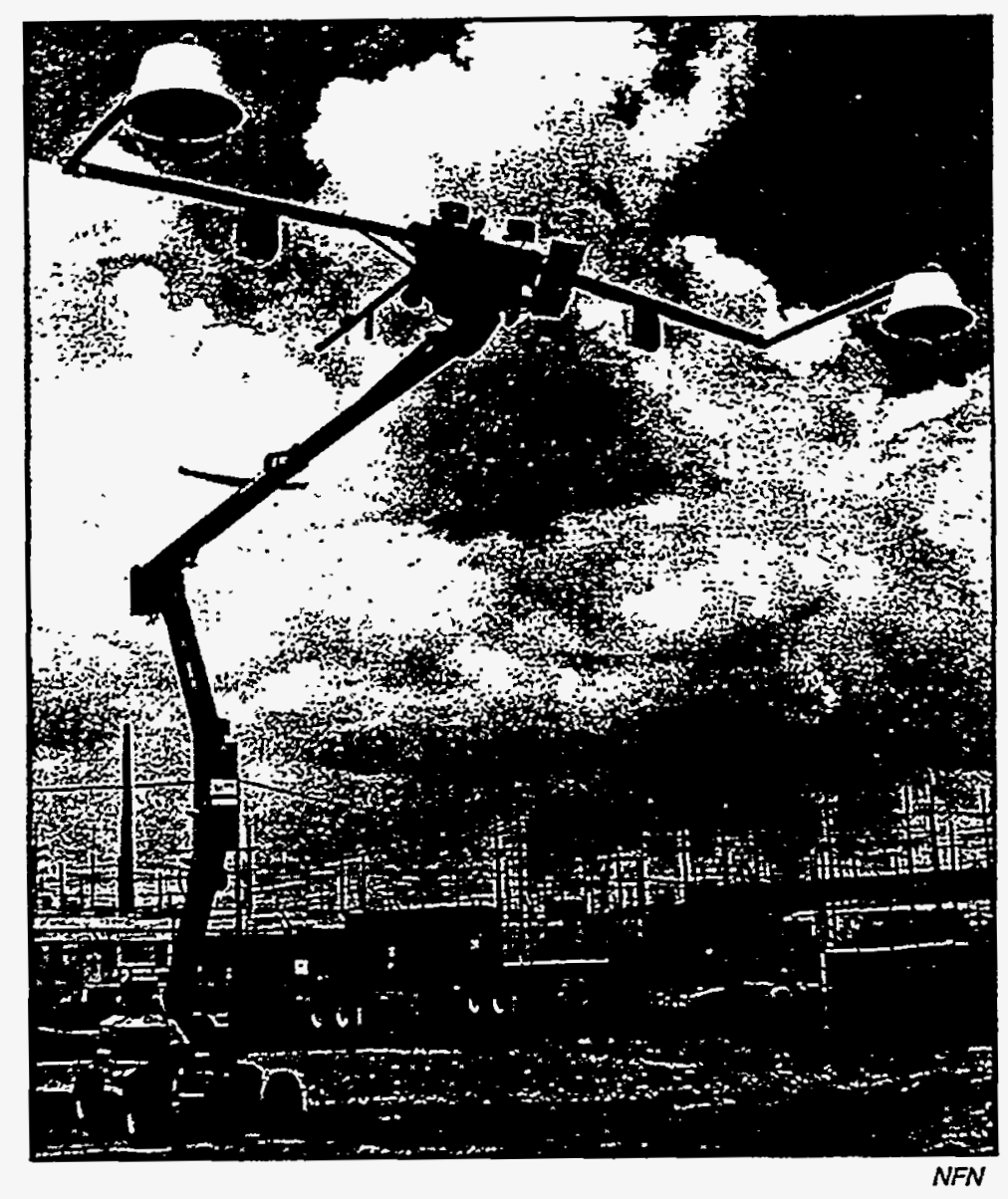

\section{ROVER}

The Remote Overhead Video Extendible Robot (ROVER) was developed by SRTC to provide multiple overhead video views of radioactive crane access worksites, which eliminates the need for direct viewing. The system is controlled from a control van up to 100 feet away. ROVER unfolds and can reach 30 feet beyond its base and up to 45 feet from the ground. All controls and video signals are multiplexed over three coaxial cables. It includes remotely controlled high-intensity lights, microphones and speakers. ROVER has been successfully deployed in several radiation worksites to move piping and pumps, and to clean up high level contamination sites. It is used routinely in the SRS Waste Tank Areas. ROVER eliminated the need for personnel to be positioned at the worksite, exposed to radiation, to direct a crane operator with hand signals, as was done previously. 


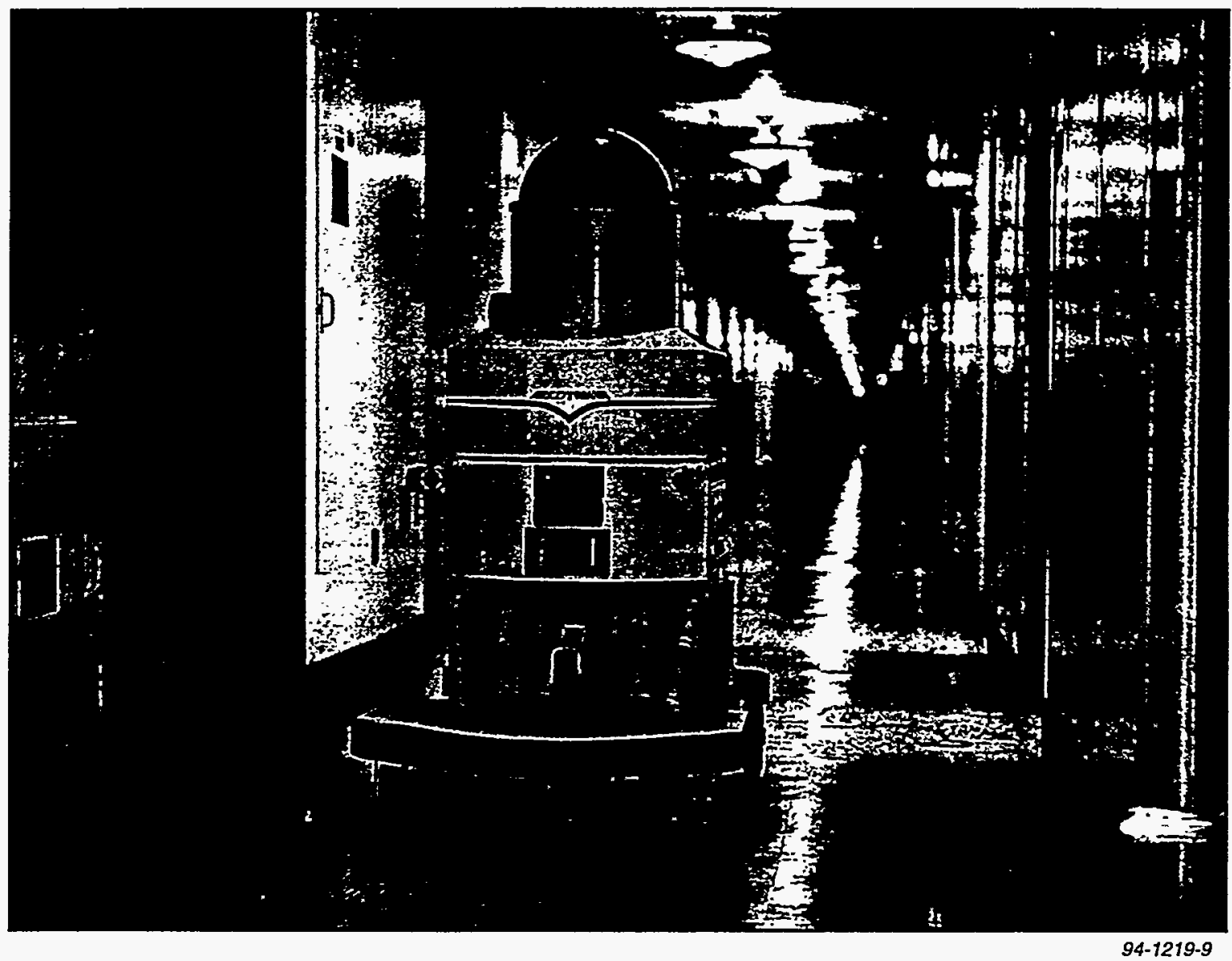

\section{SIMON}

After a contamination incident in the SRTC main laboratory building, the Semi-Intelligent Mobile Observing Navigator (SIMON) was used to survey corridors. SIMON surveyed the corridors in the basement of the laboratory building and found over 20 spots of beta contamination that were not previously detected by manual survey. All the spots found by SIMON were confirmed by Health Physics personnel and subsequently cleaned up.

SIMON is based on a Cybermotion K2A mobile robot and has been outfitted with gas proportional radiation detectors and a radiation computer. This application of a mobile robot has been patented by SRTC. SIMON can be programmed to survey corridors autonomously. The robot moves at one inch per second while surveying to detect the low levels of radiation required. The data can be displayed in a color-coded map of the facility called RADMAP. RADMAP is being copyrighted by SRTC. SIMON also found a spot of contamination during a demonstration at Oak Ridge National Laboratory. No contamination was expected during the demonstration and the spot was $600 \mathrm{dpm}$, well below the limit for a "clean" area of 1,000 dpm. However, it demonstrated that this SRTC patented technology can detect all contamination at or above established limits. 

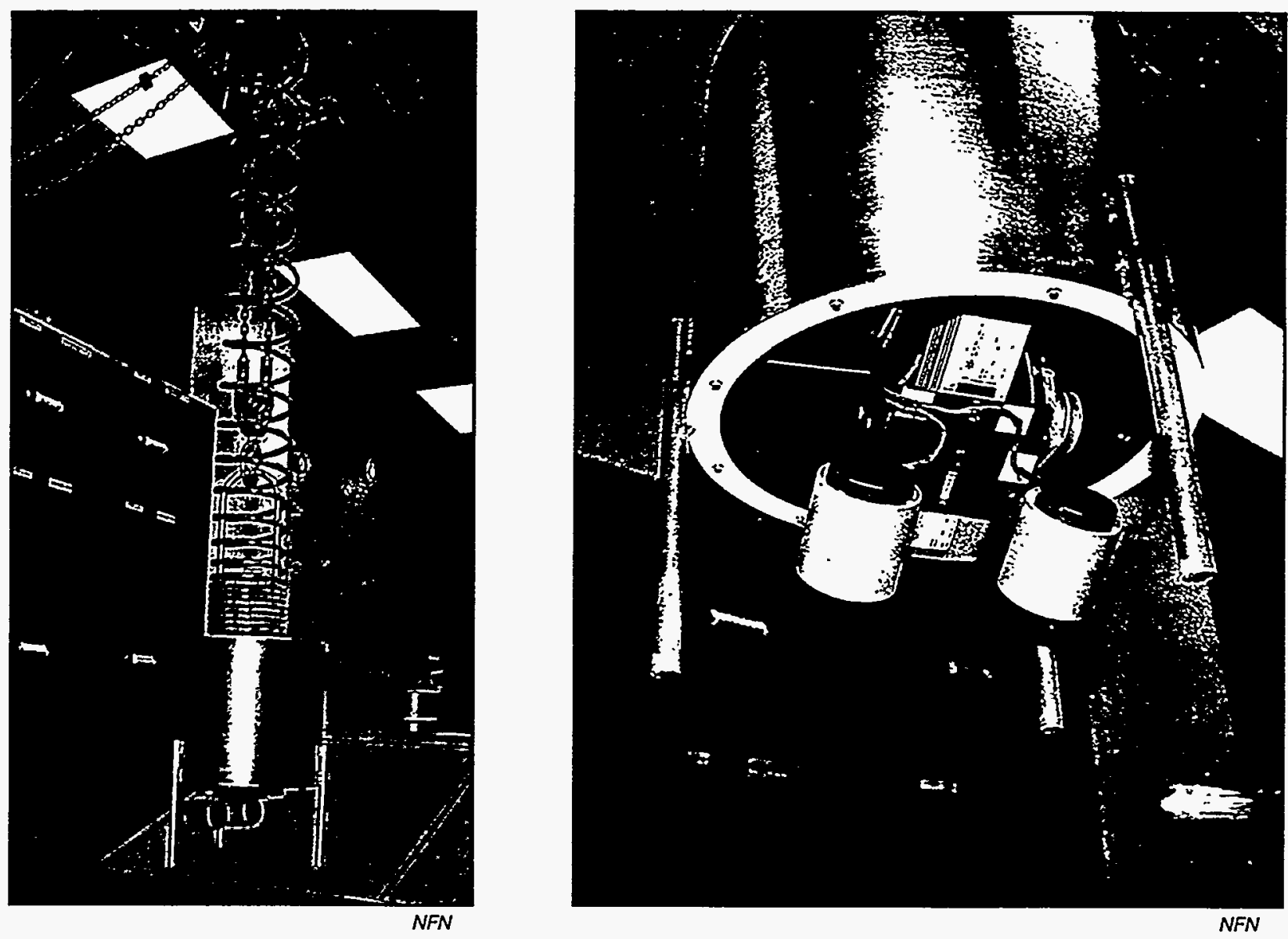

\section{Camera In A Drum}

A remote camera system was developed for deployment with the existing cranes in the SRS canyons. The camera, light, and pan and tilt units are mounted within a protective housing and the power, controls, and signals are carried within coiled tubing, utilizing a specialized wiring technique. This allows the system to be manipulated by an existing hoist on the canyon cranes. This system provided the first view of many areas in the canyon (i.e. inside vessels and under vessels) since the canyons were built in the 1950's and has assisted in diagnosing and evaluating problems in the canyon facilities. The first system functioned so well that several systems were subsequently built and are used in both SRS canyon facilities. 


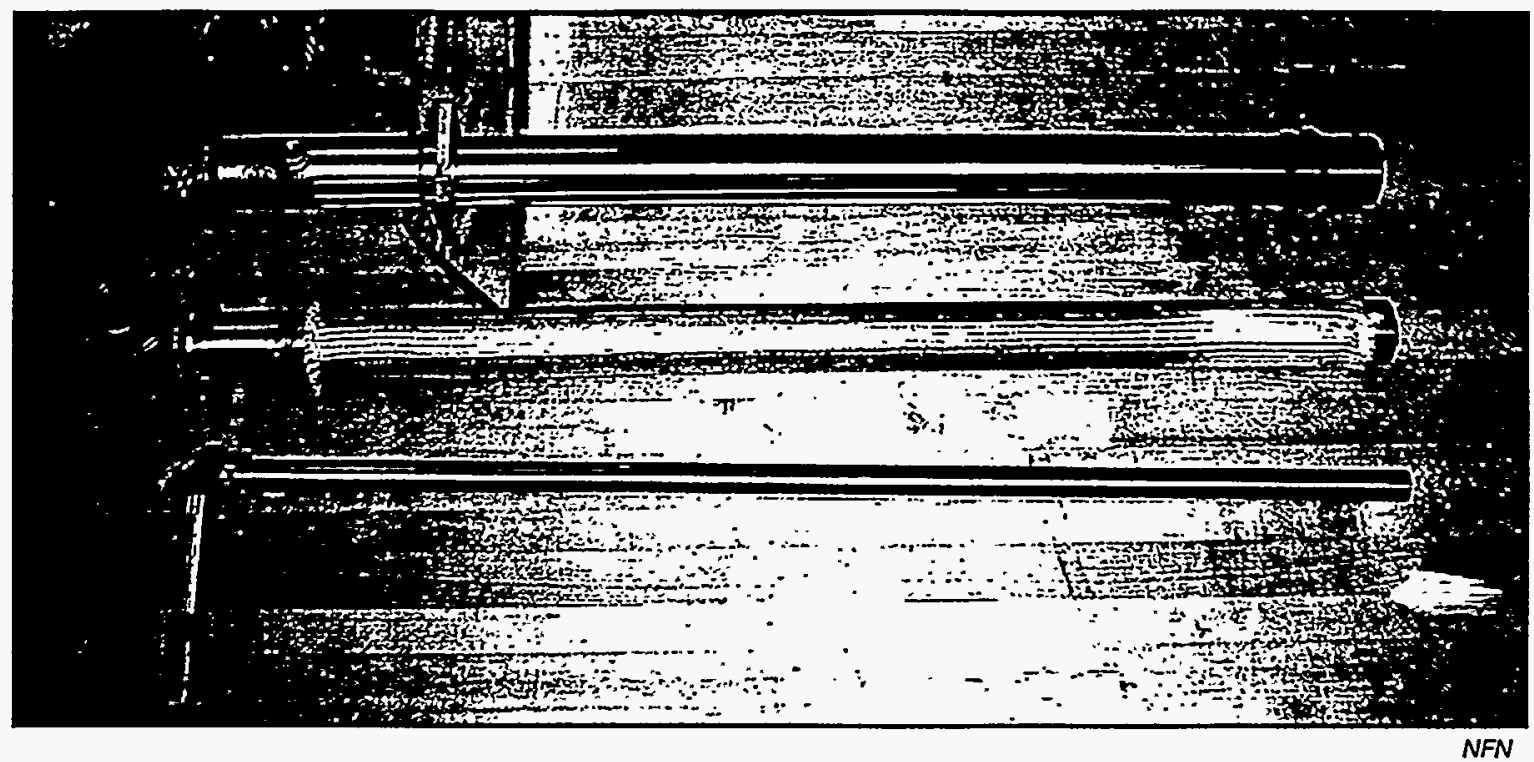

\section{DWPF Melter Borescope}

SRTC designed and developed a borescope used to observe the interior of the glass melter in the Defense Waste Processing Facility (DWPF). The borescope must operate in the remotely operated melter cell in the vapor space above the glass. The glass temperature is above $1,200^{\circ} \mathrm{C}$. The borescope is fully radiation hardened and protected from the extreme environment of the melter interior, to provide continuous viewing of the glass surface during all operations. Initial operation of the borescope in non-radioactive testing of the melter uncovered problems with optics and erosion of the borescope. SRTC is assisting with resolution of these problems. 


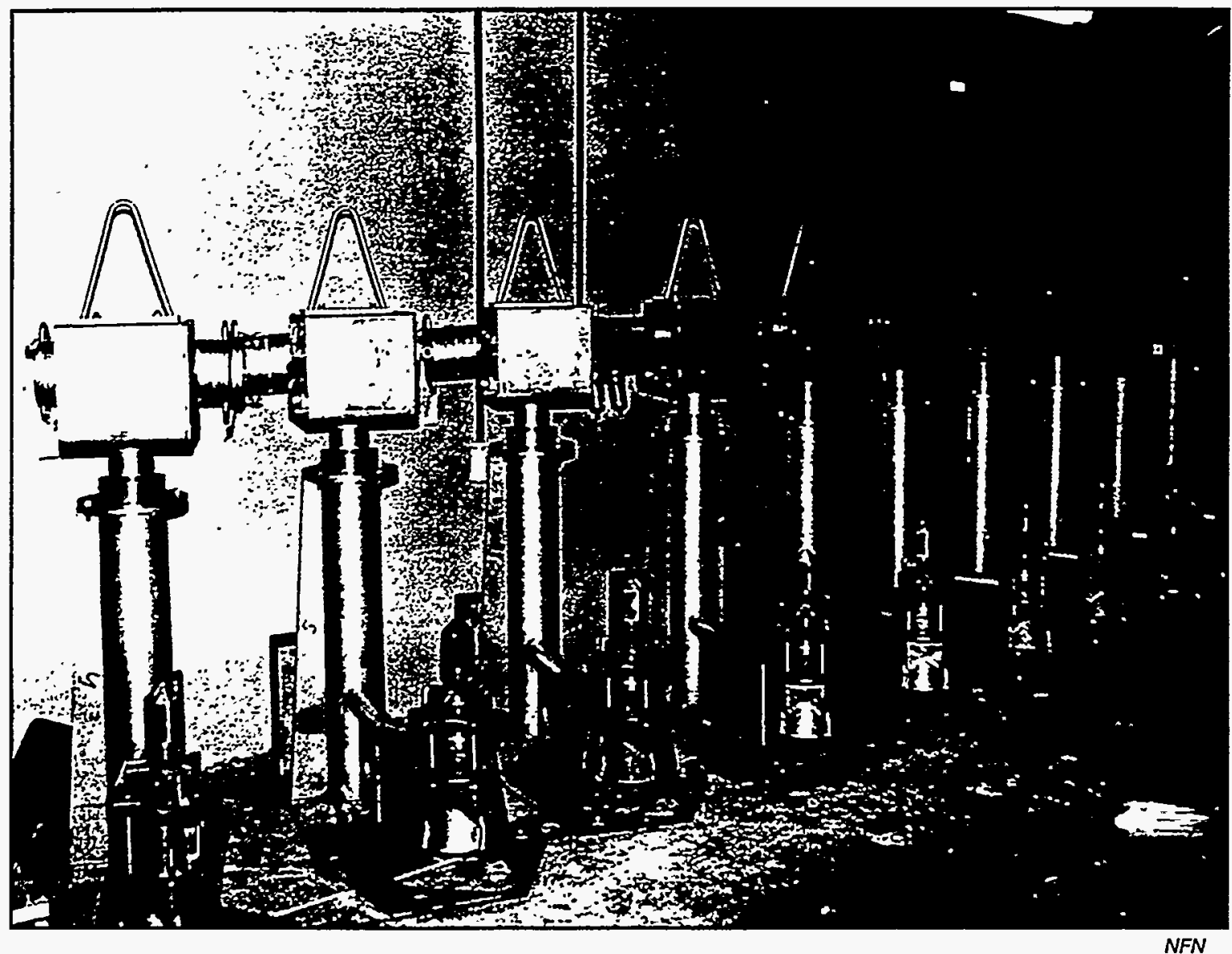

\section{DWPF Cameras}

SRTC developed unique camera systems for the DWPF that required remote installation and removal of the cameras. The task required development of a new jumper design that contains all the power, control, and signals required for operation. The components are sealed inside stainless steel cases for protection and include pan and tilt mechanisms. The fully radiation hardened systems provide a variety of continuous video views inside of the very high radiation environment of a processing canyon. 


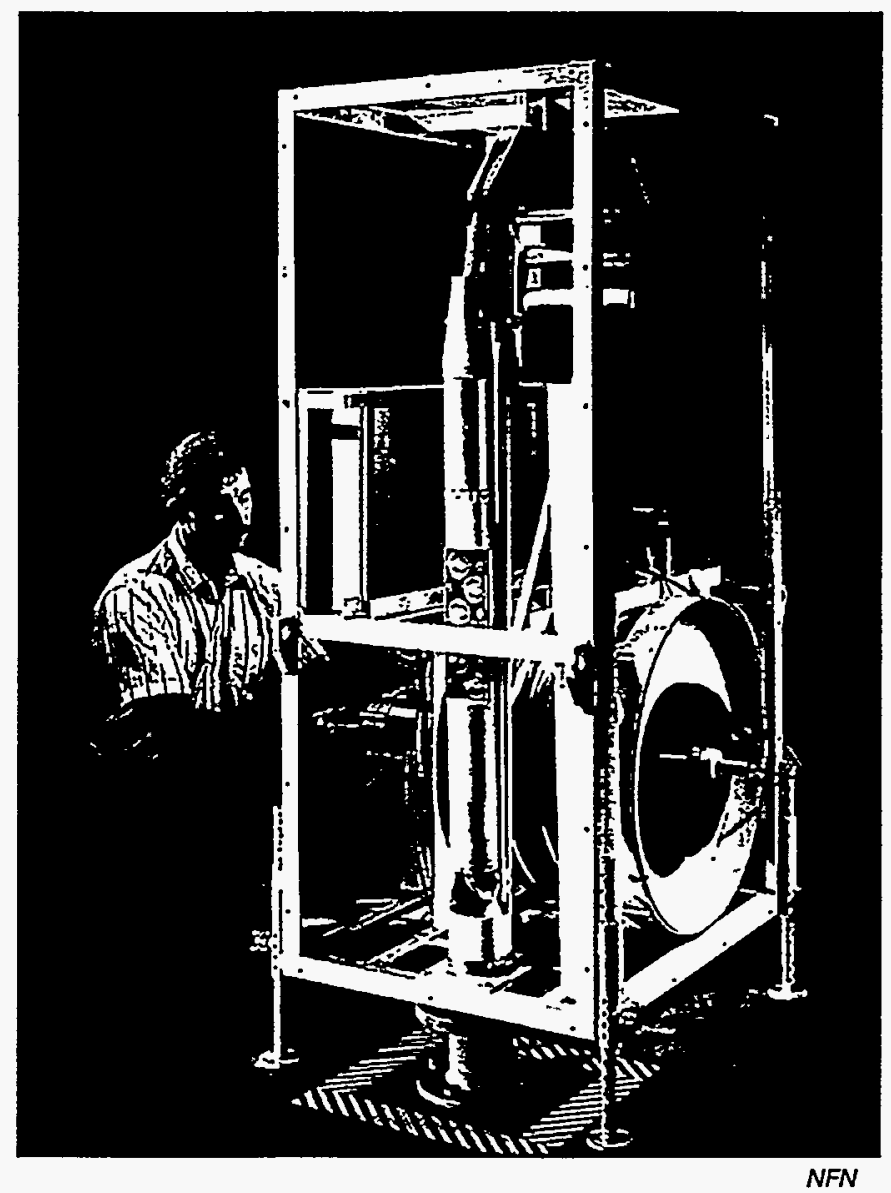

\section{Hanford Waste Tank Camera System}

SRTC has developed and delivered remote camera systems for the Hanford waste tanks. The cameras are required for inspection of the tanks and during cleanup operations in the tanks, including the control of large robotic arms. The camera, light and camera aiming systems have to fit through a 4-inch "riser" pipe that extends up to 15 feet down to the tank and then travel to the bottom of the tank that is approximately 30 feet deep. The system design is based on SRTC experience gained from systems developed for SRS. All camera, lens, lighting, and deployment controls are linked over fiber optic cables to personnel located over 900 feet away. The systems include fully radiation-hardened and color stereo viewing versions, to be used in overseeing the remediation of underground storage tanks. 


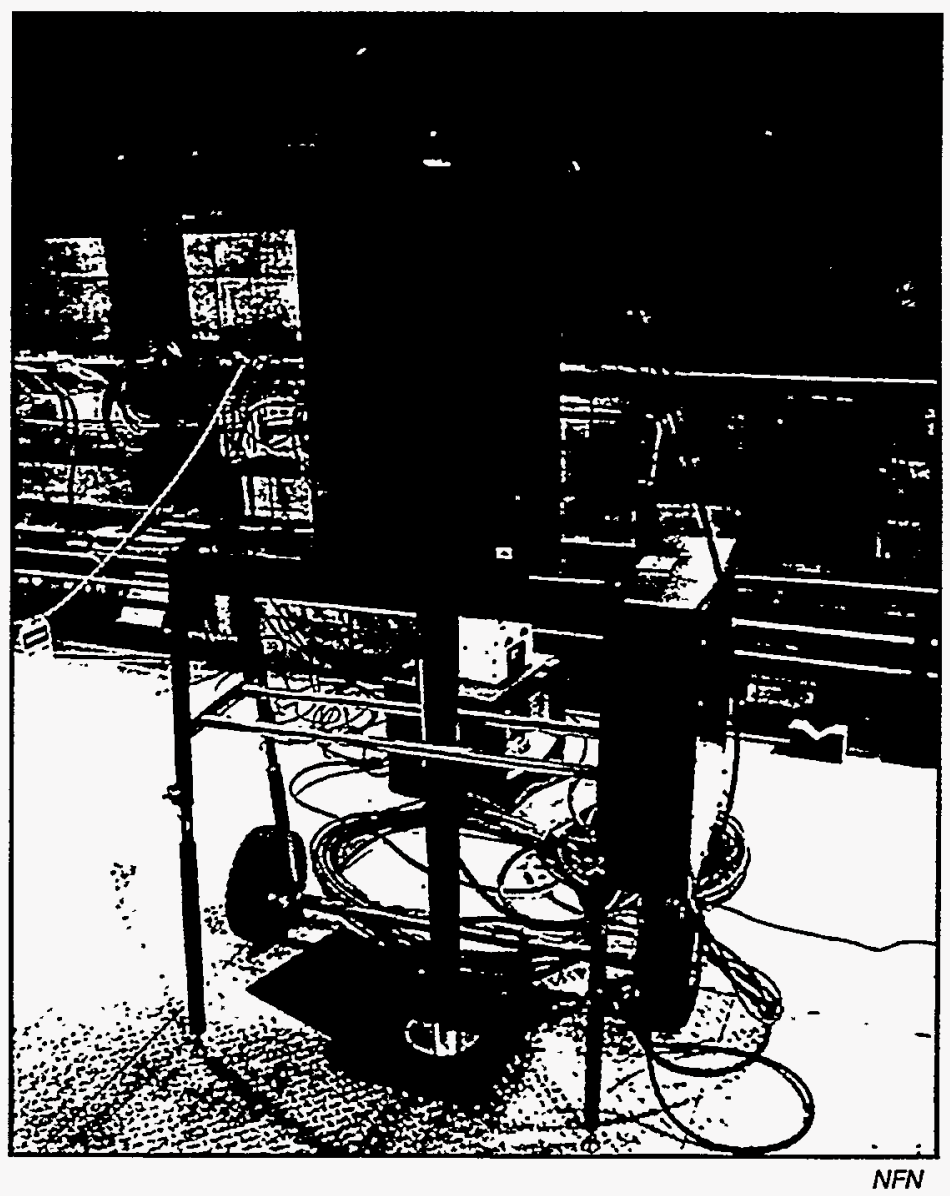

\section{In-Tank Precipitation Camera System}

SRTC developed a camera system to be used in SRS tanks during operation of In-Tank Precipitation (ITP). The camera, light, and pan system have to fit through a 5 -inch "riser" pipe that extends up to 15 feet down to the tank and then travel to the bottom of the tank that is approximately 30 feet deep. The system design is based on SRTC experience gained from other systems developed for SRS. The unit is designed to Class 1, Division 1, flammable atmosphere standards, utilizing a unique method of housing and deployment cable pressurization, to meet the ITP requirement. All camera, lighting, and deployment controls are from a remote location away from the radiological hazards of the tank riser. 


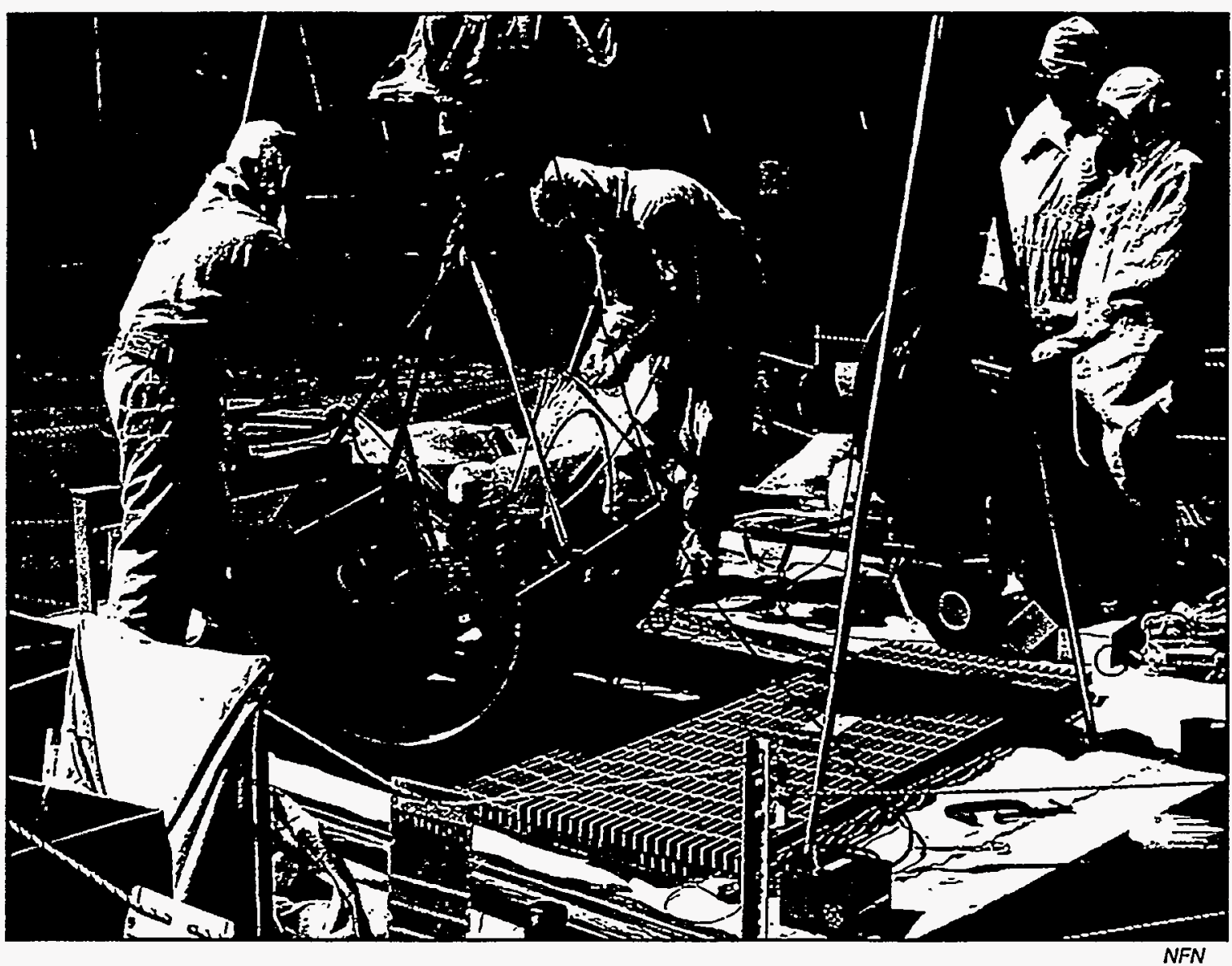

\section{F-Area Retention Basin Pipe Crawler}

SRTC developed a pipe crawler with video and radiological survey capabilities to investigate a process sewer line leading to the F-Area Retention Basin. Even though the basin had been previously closed and the sewer line abandoned, the Comprehensive Environmental Response, Compensation, and Liability Act (CERCLA) required a survey of the pipe line. It was proposed that 300 random soil samples be made along the length of the line with access by several manholes over its length. The process sewer line is composed of 24-inch and 36-inch pipe sections. An internal survey using a pipe crawler was proposed as a means of reducing the number of proposed soil samples by identifying if and where high concentrations of radiation existed. The pipe crawler system included a commercially available crawler from Inuktun Services of Canada, three radiation detectors, a low light level camera and a light. A unique deployment system was developed to lower the crawler into each manhole and to insert the crawler into the pipe, which eliminated the need for human entry to a confined, radiological space. A 500-foot umbilical cord deployed from cable reels mounted on hand trucks provided power and control signals. The base station included; a control console, video monitor, and survey instruments that could record radiological data. Over 800 feet of process sewer line was inspected by the crawler. Several areas of elevated radiation were identified. Use of the pipe crawler reduced the number of soil samples required from 300 to 8 for a significant cost reduction and also provided documentation on the condition of the pipe line. 


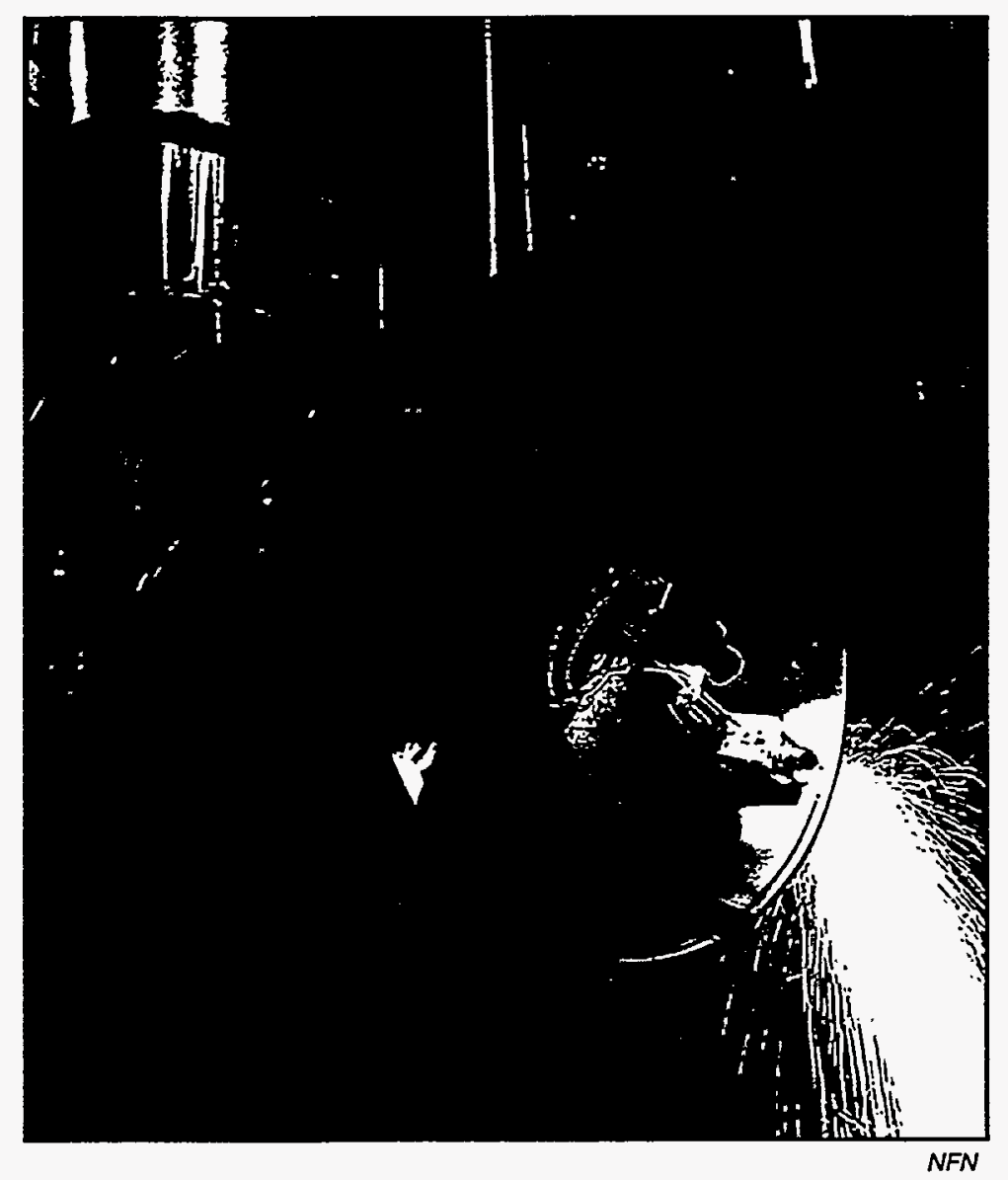

\section{F-Canyon Elbow-Cutting Pipe Crawler}

SRTC has developed a pipe crawler capable of crawling through over 230 feet of 36 -inch diameter contaminated ventilation pipe and removing an elbow by cutting from the inside. $A$ 45-degree branch intersection and a gooseneck must be traversed. The elbow must be removed to redirect air flow in case of fire at the SRS F-Canyon facility. This task is part of a WSRC award fee item. Radiation levels, high air flow and physical restraints precludes performing this task manually. A pneumatically-powered inch worm type pipe crawler for the 36 pipe has been developed. The cutting attachment at the front of the crawler manipulates a plasma arc torch to make two full cuts above and below the elbow through the 1/4-inch stainless steel pipe wall. Even the plasma arc torch is unique with a 230 -foot lead. Two camera and light systems are included to observe the front and back section of the crawler as well as the torch. 


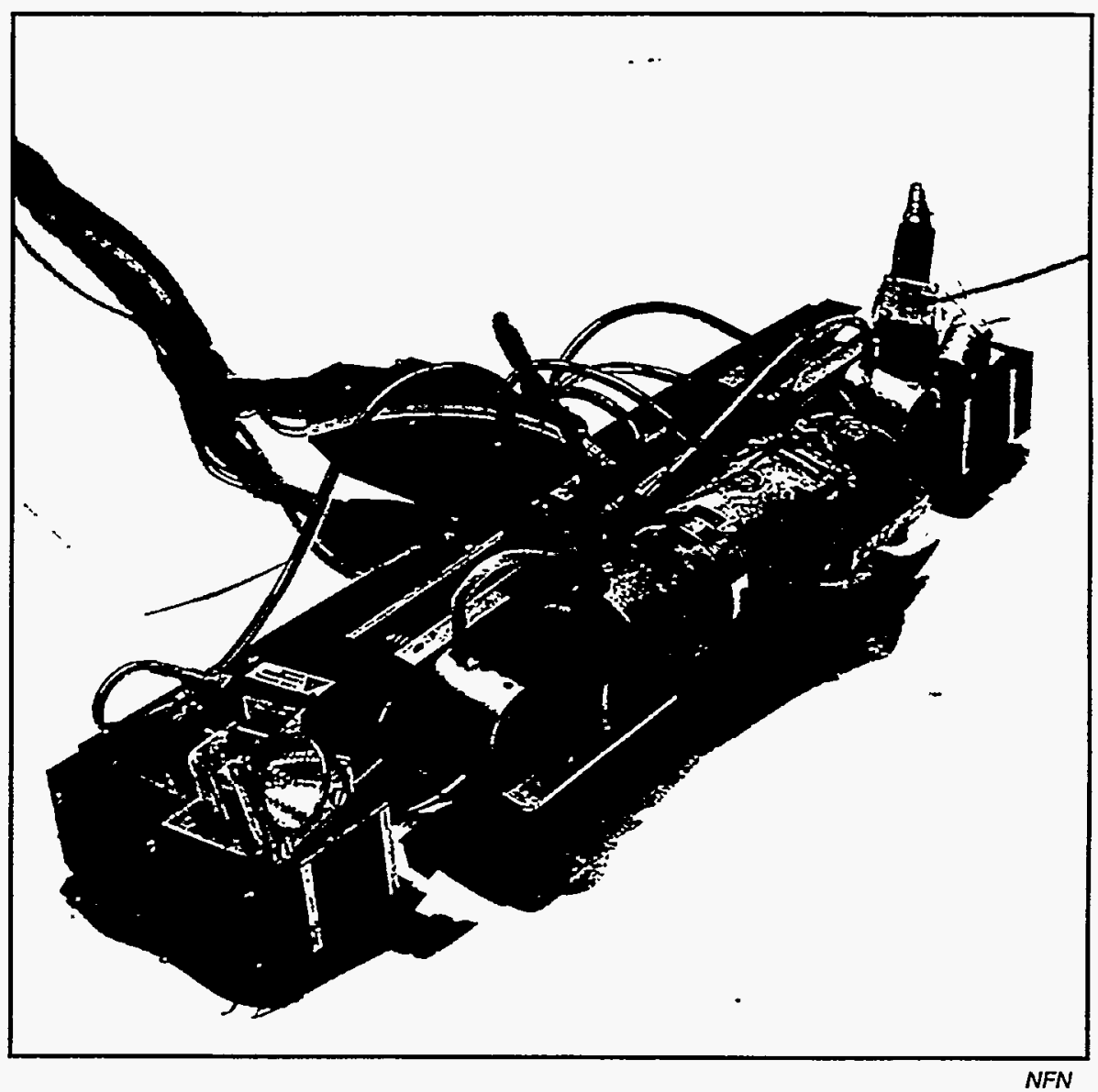

\section{Waste Tank Wall Crawler}

A family of wall crawlers has been developed for inspection of carbon steel waste tanks from the annular space. Three magnetic wheeled crawlers have been developed and deployed at the Savannah River Site and the West Valley Site including a Surface Preparation Crawler, an Ultrasonic Crawler, and a Camera Crawler. A deployment tool was developed that launches and retrieves the crawlers from the tank wall. These systems meet the requirements of ASME Section V, Article 5 and of the "Proposed Nondestructive Examination (NDE) Standard for High-Level Waste Tanks". One or two crawlers are placed on the Deployment Tool. This tool is 10 inches in diameter and 7 feet long. The tool is lowered into the annular space through a riser. Legs on the tool extend to force the tool against the tank wall so that the crawlers can be driven off or on. The Surface Preparation Crawler incorporates a wire brush to prepare a rough surface for ultrasonic testing. The Ultrasonic Crawler interfaces with an ABB Amdata I-PC Ultrasonic Data Acquisition System. Efficient use of water for the ultrasonic couplant results in the water evaporating before it reaches the bottom of the tank exterior. The ultrasonic sensor is spring loaded to maintain proper wall contact and the sensor can be driven side to side with a ball screw drive. The Camera Crawler includes three cameras, with one camera mounted on a articulated arm, and six lights and is used for visual inspection. The system has been used at the West Valley tank 8D-1. The system was used in SRS tank 50 and is planned for use in numerous other SRS tanks. 


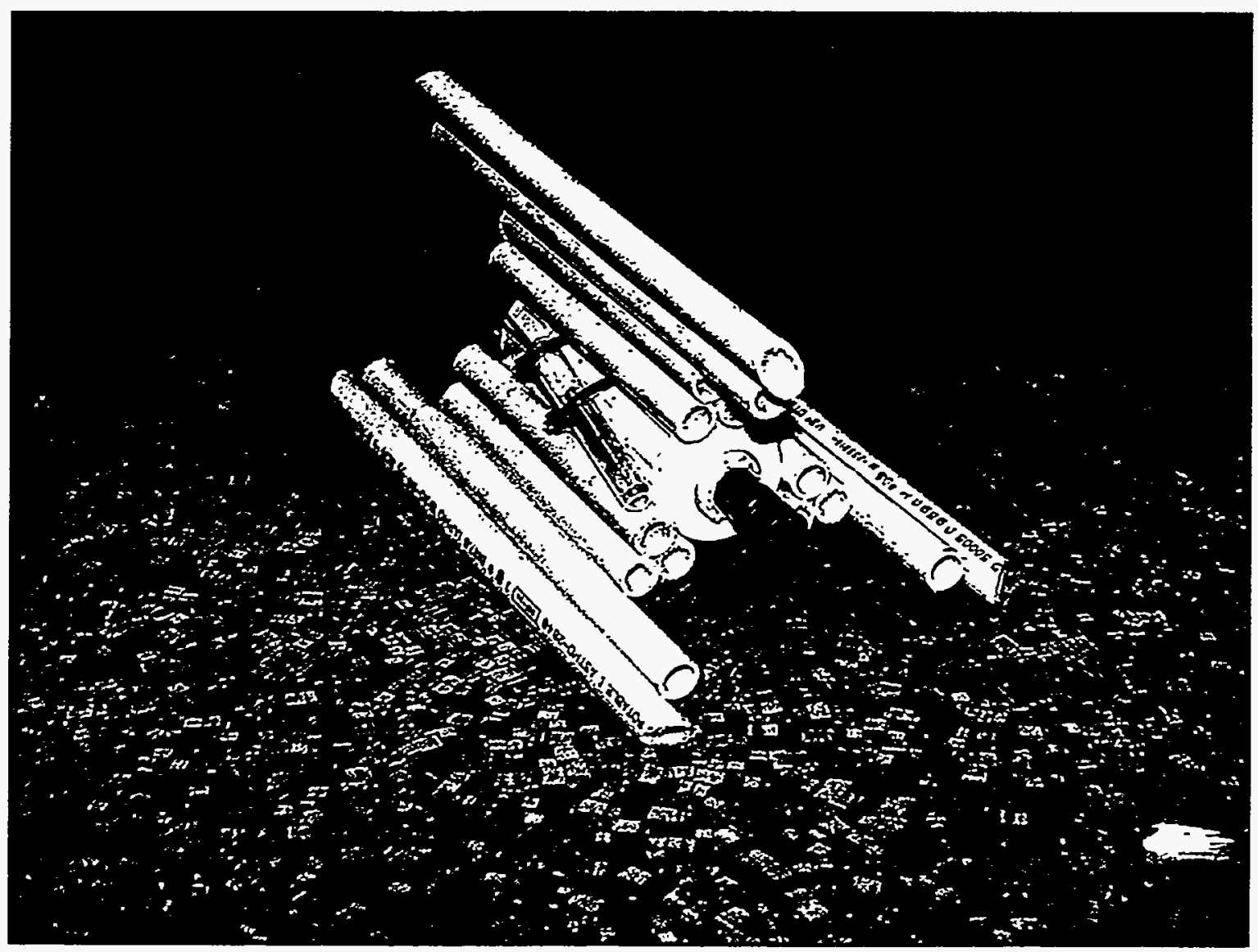

NFN

\section{Plutonium in Duct Inspection}

SRTC developed a low cost, disposable camera system to inspect a duct in the SRS F Area for potential plutonium contamination. The camera system was supported on runners made from plastic pipe to provide the proper elevation of the camera and lights and allow the system to be easily pushed through the 100-foot long duct with an umbilical cord. The umbilical cord contained all power and signal cables and was encased in a plastic hose to allow flexibility, but enough stiffness to allow pushing the system in the duct, while minimizing the contamination problems. Plutonium contamination was identified and located so that the contamination could be later found and removed. The disposable design was justified because the equipment became so contaminated during the inspection that it had to be disposed of as waste in multiple drums. The entire duct system was successfully cleaned utilizing nine camera systems without any significant personnel exposure, and no uptake of contamination. 


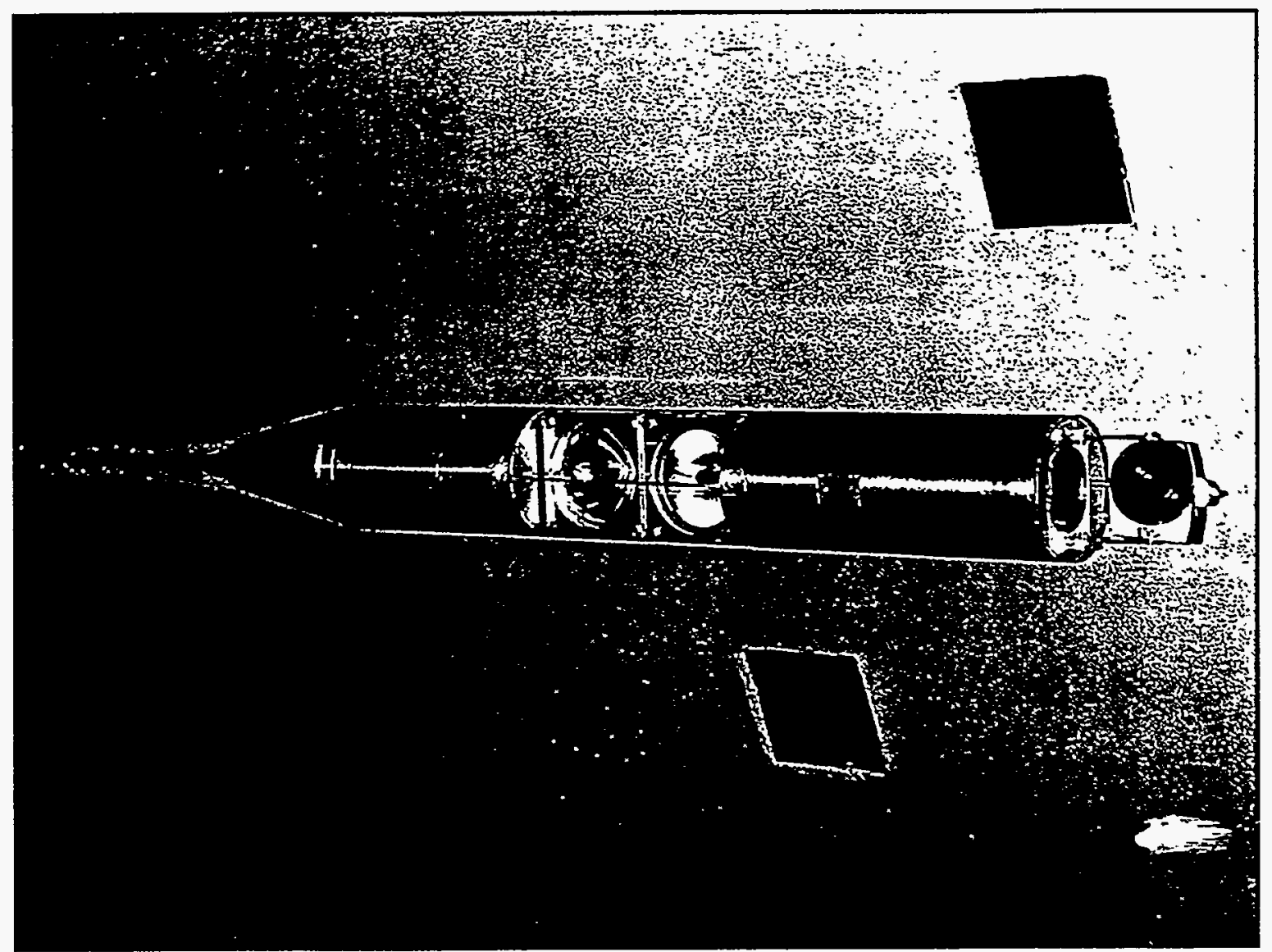

NFN

\section{Waste Tank Annulus Camera}

SRTC developed camera systems to inspect the annulus around the SRS waste tanks. The SRS waste tanks are approximately 80 feet in diameter and 30 feet high with an annular space around the tank that is 3 feet wide. Entry to the annulus is through "riser" pipes that are 5 inches in diameter. Radiation levels in the annulus can be as high as $200 \mathrm{R} / \mathrm{hr}$. The camera systems are deployed up to 50 feet from a reel. The system includes lights, camera rotation, and depth readout functions. They have been used in inspections of several tanks at SRS. All camera, lens, and lighting functions are controlled over a simplified, single coax system, by remotely located personnel. No presence is required at the riser opening during the inspection, thus significantly reducing personnel exposure. 


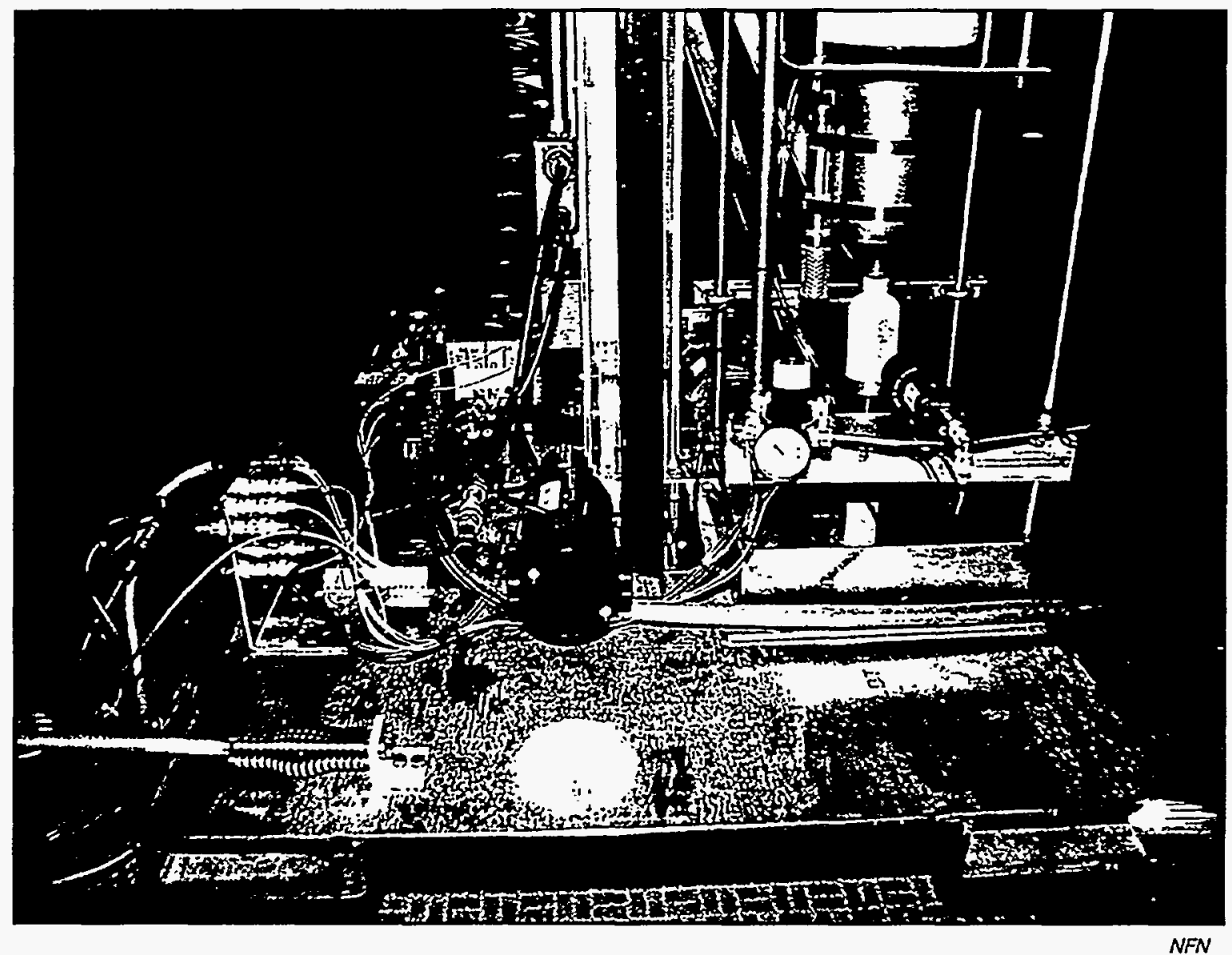

\section{Deionizer Resin Sampling}

SRS is required to sample the resin in several deionizer resin vessels. Because of the radiation of up to $5 \mathrm{R} / \mathrm{hr}$ at the surface of the vessels and potential exposure to the resin, SRTC has been requested to develop a remote method of obtaining the resin samples. $A$ vacuum actuated sampling platform was developed. The platform is lifted into place by a fork truck. The fork truck driver positions the platform above the resin vessel and removes the vessel's flange. The driver leaves the area and a motor driven sampling tube is inserted into the opening. A vacuum is used to draw the sample out into a $135 \mathrm{ml}$ bottle. The exhaust air from the operation is sent through a HEPA filter. The tube is then removed and the flange replaced so that operators can again enter the room to complete the operation. 